\title{
Mapping of Sicilian Pocket Beaches Land Use/Land Cover with Sentinel-2 Imagery: A Case Study of Messina Province
}

\author{
Giovanni Randazzo ${ }^{1,2,3}$, Maria Cascio ${ }^{1}$, Marco Fontana ${ }^{1}$, Francesco Gregorio ${ }^{1}$, Stefania Lanza ${ }^{1,2}$ \\ and Anselme Muzirafuti ${ }^{1, *(D)}$
}

1 Interreg Italia-Malta-Project: Pocket Beach Management \& Remote Surveillance System (BESS), University of Messina, Via F. Stagno d'Alcontres, 31-98166 Messina, Italy; giovanni.randazzo@unime.it (G.R.); maria.cascio86@gmail.com (M.C.); marco.fontana92@yahoo.it (M.F.); gregoriofrancesco92@gmail.com (F.G.); stefania.lanza@unime.it (S.L.)

2 GeoloGIS s.r.l. Spin Off of University of Messina, 98166 Messina, Italy

3 Dipartimento di Scienze Matematiche e Informatiche, Scienze Fisiche e Scienze della Terra, Università degli Studi di Messina, Via F. Stagno d'Alcontres, 31-98166 Messina, Italy

* Correspondence: a.muzirafuti@edu.umi.ac.ma or muzansel@gmail.com; Tel.: +39-3312976306

Citation: Randazzo, G.; Cascio, M.; Fontana, M.; Gregorio, F.; Lanza, S.; Muzirafuti, A. Mapping of Sicilian Pocket Beaches Land Use/Land Cover with Sentinel-2 Imagery: A Case Study of Messina Province. Land 2021, 10, 678. https://doi.org/ 10.3390/land 10070678

Academic Editor: Karel Charvat

Received: 26 May 2021

Accepted: 24 June 2021

Published: 27 June 2021

Publisher's Note: MDPI stays neutral with regard to jurisdictional claims in published maps and institutional affiliations.

Copyright: (c) 2021 by the authors. Licensee MDPI, Basel, Switzerland. This article is an open access article distributed under the terms and conditions of the Creative Commons Attribution (CC BY) license (https:// creativecommons.org/licenses/by/ $4.0 /)$

\begin{abstract}
Pocket beaches (PBs) are among the most attractive tourist sites and economic development contributors in coastal areas; however, they are negatively impacted by the combined effects of climate change and anthropogenic activities. Generally, research on PBs is conducted from the beach towards offshore. Studies on the land use/land cover (LULC) of PBs are limited and currently lacking. Such studies deserve more investigation due to the importance of LULC in PBs' functioning. In this study, supervised classification methods were investigated for LULC mapping of the PBs located in the province of Messina. Sentinel-2B satellite images were analyzed using maximum likelihood (MaL), minimum distance (MiD), mahalanobis distance (MaD) and spectral angle mapper (SAM) classification methods. The study was conducted mainly in order to determine which classification method would be adequate for small scale Sentinel-2 imagery analysis and provide accurate results for the LULC mapping of PBs. In addition, an occurrence-based filter algorithm in conjunction with OpenStreetMap data and Google Earth imagery was used to extract linear features within $500 \mathrm{~m}$ of the inland buffer zone of the PBs. The results demonstrate that information on the biophysical parameters, namely surface cover fractions, of the coastal area can be obtained by conducting LULC mapping on Sentinel-2 images.
\end{abstract}

Keywords: land use/land cover; climate change; OpenStreetMap; earth observation satellites; pocket beach; maximum likelihood; minimum distance; mahalanobis distance; spectral angle mapper; image classification

\section{Introduction}

Pocket beaches (PBs) are small beaches limited by natural rocky headlands or artificial structures [1-3]. These headlands prevent longshore sediment transport and bestow natural protection to the PBs. Depending on the level of their protection, PBs are often considered as closed systems. These enclosed beaches are the most attractive tourist sites and economic development contributors in coastal areas [4,5]; however, the combined effects of climate change and anthropogenic activities put pressure on the coastal landscapes [6] of these ecological niches, consequently impacting their economic value. Within a buffer zone of $500 \mathrm{~m}$ from the shoreline, samples representing the main land cover classes of the PBs were selected and extracted from Sentinel-2 imagery. The area of study was chosen in order to evaluate if the adopted approach would be an adequate study model for other different PBs. For each PB, a number of polygon shapefiles for a class of LULC were manually digitized. We separated the samples for the training of the classification model from the samples used for validation and accuracy assessment of the classification results. The validation 
samples were selected by adopting photointerpretation [7]; Sicilian Corine Land Cover, Sentinel-2B, and Google Earth imagery were acquired for different dates. The part of the image attributed to water also has minimal percentages because the sea was previously cut out; however, for the PBs located near cliffs, a small part of the sea water was taken into consideration.

Generally, research on PBs is conducted from the beach towards offshore areas [8-10]. Most research has focused on planview geometry and morphological characteristic analysis of PBs $[11,12]$ or morphohydrodynamics investigations $[10,13]$. Studies on the land use of PBs [14-16] are limited and currently lacking. However, such studies deserve to be considered and conducted due to the importance of LULC in PB function.

Earth observation satellite imaging is the most cost-effective source of data for managing, mapping, and monitoring both offshore [17] and onshore [18,19] coastal areas [20]. It is useful in monitoring anthropogenic coastal activities, such as forestry and agriculture [21], construction [22], mining [23], transport and navigation [24], tourism and recreation [6], fishing and aquaculture [25-27], and shipping operations [28]. A significant amount of the world's population occupies or otherwise visits coastal areas [29], and their activities are increasing and putting pressure on the local environment. It is essential to conduct regular monitoring to identify and evaluate the impact of anthropogenic activities in these areas. Globally, many studies have been carried out in coastal areas using freely available earth observation data $[6,30,31]$, although these studies were conducted on a large scale.

This study is a part of the products of the Pocket Beach Management and Remote Surveillance System (BESS) projects, cofinanced by the European Regional Development Fund, within the Interreg Italy-Malta 2014-2020, and coordinated by the University of Messina in collaboration with the Ministry of Gozo (MG), Euro-Mediterranean Center on Insular Coastal Dynamics-University of Malta (UM), University of Palermo (UNIPA), and the National Institute of Geophysics and Volcanology (INGV).

In this study, supervised classification methods were investigated for LULC mapping of the 24 PBs located in the province of Messina. Sentinel-2B satellite images were analyzed using maximum likelihood (MaL) [32], minimum distance (MiD) [33], mahalanobis distance (MaD) [34] and spectral angle mapper (SAM) [35] classification methods. The study was conducted mainly in order to determine which classification method would be most suitable for small scale Sentinel-2 imagery analysis, aiming for the extraction of information on biophysical parameters, namely surface cover fractions, by conducting LULC mapping, and to provide accuracy results for LULC mapping in the $500 \mathrm{~m}$ buffer zone of the PBs.

\section{Materials and Methods}

\subsection{Area of Study}

Within the BESS Project, we studied 132 PBs located on the main and minor islands of Sicily, Malta, and Gozo. We collected information about sediments (grain size, color, and composition) and coastal evolution using drone and satellite images. The shape parameters [11,12] of the bay were manually digitized based on $25 \mathrm{~cm}$ spatial resolution orthophotos obtained from the 2013 virtual hub dataset (Web Map Service) [36], which was gathered via bathymetry by direct survey or indirect analysis, and a $500 \mathrm{~m}$ land use buffer derived from satellite images. Geographic information system (GIS) analysis was applied for data processing and mapping to provide both management and maintenance systems based on the integrated knowledge of these environmental niches [37].

The PBs are closed environments that, considering their degree of confinement, can be considered relicts: a witness of an exceptional storm or a tsunami; the transition of sediments coming from an overflow; the continuous feeding of streams; or the sudden fall of a cliff. The interest of our project was to include an analysis of the potential impact of territorial pressure on the evaluation. In a territory with an estimated density of 192.3 habitants per $\mathrm{km}^{2}$ [38] and with significant tourism (14-15 million tourists in Sicily in the pre-COVID-19 era [39]) frequenting the beaches, both "standard" or pocket, the ecological status greatly suffered as a result. For this reason, it is useful to perform an 
LULC analysis by taking advantage of recent technological development in remote sensing by using the available means-satellite images and commercial software algorithms. To define the methodology, the 24 PBs in the Province of Messina (Figure 1) were chosen because it has the longest coastal perimeter, about $412.65 \mathrm{~km}$ (more than $\frac{1}{4}$ of the whole considered territory), and its coastline is exposed to the waves of two different seas: the Ionian from the east and the Tyrrhenian from the north. Furthermore, the coastal area shows a different state of urbanization because of its variability of both morphology and geodiversity. Alluvial plains derived from the dismantlement of the back chain are characterized by different grades of metamorphic outcropping. From 2001 to 2019 [40], the area of study saw slight demographic changes (Table 1), the population decreasing on the main island and increasing on the Aeolian Islands. During the summer, the population everywhere increases by approximately $30 \%$ (based on media information and personnel observations; no punctual scientific data), with the highest peaks on the minor islands.
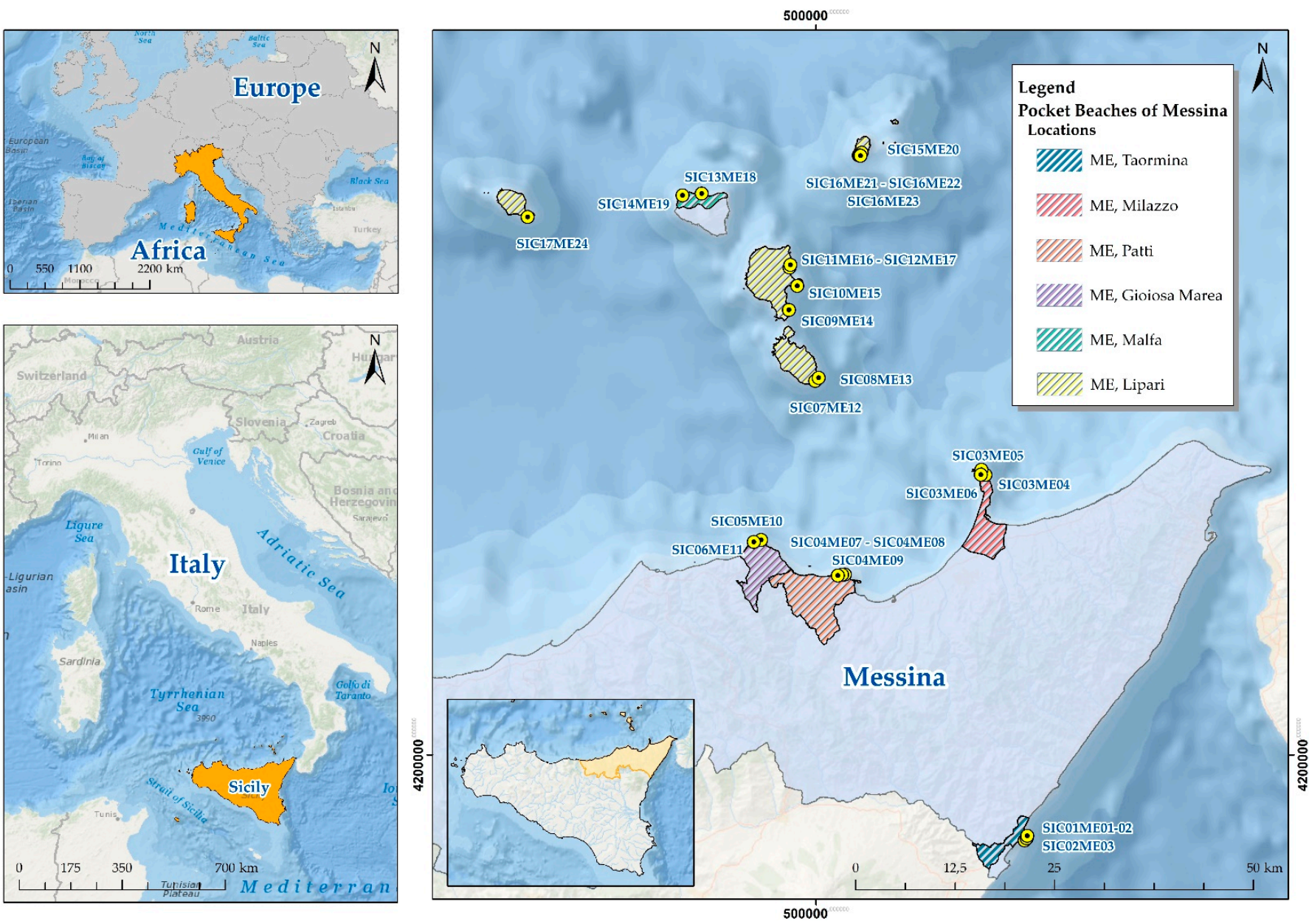

Figure 1. Location of 24 PBs studied on the coast of six municipalities (Taormina, Milazzo, Patti, Gioiosa Marea, Lipari, and Malfa) of the province of Messina. From the southeast to northwest of Messina province, we studied 3 PBs on the coastal city of Taormina, 3 PBs on the coast of Milazzo, 3 PBs on the coast of Patti, 2 PBs on the coast of Gioiosa Marea, 11 PBs on the coast of Aeolian Island (Lipari), and 2 PBs on the coast of Malfa. 
Table 1. Population and area of coastal municipalities of the province of Messina affiliated with the pocket beaches (PBs) studied in the BESS project.

\begin{tabular}{cccccccc}
\hline Municipalities & $\begin{array}{c}\text { Population } \\
\text { in 2001 }\end{array}$ & $\begin{array}{c}\text { Population } \\
\text { in 2006 }\end{array}$ & $\begin{array}{c}\text { Population } \\
\text { in 2010 }\end{array}$ & $\begin{array}{c}\text { Population } \\
\text { in 2013 }\end{array}$ & $\begin{array}{c}\text { Population } \\
\text { in 2016 }\end{array}$ & $\begin{array}{c}\text { Population } \\
\text { in 2019 }\end{array}$ & $\begin{array}{c}\text { Area } \\
\left(\mathbf{k m} \mathbf{2}^{\mathbf{2}}\right)\end{array}$ \\
\hline Gioiosa Marea & 7229 & 7198 & 7209 & 7198 & 7014 & 6880 & 26.48 \\
Taormina & 10,778 & 11,026 & 11,076 & 11,050 & 10,909 & 10,844 & 13.13 \\
Milazzo & 32,083 & 32,590 & 32,601 & 31,882 & 31,473 & 30,860 & 24.7 \\
Lipari & 10,556 & 10,894 & 11,386 & 12,500 & 12,753 & 12,836 & 89.71 \\
Malfa & 847 & 872 & 943 & 996 & 956 & 987 & 8.73 \\
Patti & 13,108 & 13,391 & 13,611 & 13,420 & 13,347 & 13,066 & 50.07 \\
\hline
\end{tabular}

Along the coastline facing the Ionian Sea, there are 3 PBs in two different locations: 1 PB formed by 2 beaches in a double-curved structure due to the central presence of Isola Bella in the bay of Taormina (from the name of the homonymous municipality) and 1 PB in the bay of Mazzarò. These beaches are limited by the railway line, hotels, restaurants, and beaches of the most important tourist destination of Sicily.

Along the Tyrrhenian coast, 21 PBs were selected: 8 PBs on the main island and 13 on the Aeolian Archipelago. Three beaches, grouped into 1 PB, are located around the Milazzo Peninsula, exposed to the east, north, and west waves, respectively. The whole peninsula is part of a marine reserve, where fishing and bathing activities are strictly regulated. Three beaches, grouped into $1 \mathrm{~PB}$, are located along the northwest side of Cape Tindari and part of a natural protected area; only the westernmost PB is accessible by a very bumpy white road, and the others are accessible only by the sea. Due to this, they maintain a remarkably high degree of naturalness. The two PBs of Capo Calavà are divided by a short promontory - the east one is a very small and wild beach and very difficult to reach, whereas the western one is the longest PB in our study. The longest PB is a wide beach with the presence of the railway line situated above sea level and few activities in the most internal part of the beach itself.

The Aeolian Archipelago contains seven islands: the island of Salina, which has three municipalities - 2 PBs from our study are located on the coast of the municipality of Malfa; the other six islands are under the jurisdiction of the municipality of Lipari, which contains 2 PBs along the Volcano Island, 4 PBs along the Lipari Island, and 1 PB along the coast of the Panarea and Filicudi islands, respectively. For each beach, a BESS Project code (SIC01ME01, SIC01ME02 ... ) was assigned with letters and numbers: "SIC" to distinguish the Sicilian ones from the Malta and Gozo beaches. The first " 01 ... " represents the number of one of the 132 PBs studied along the whole Sicilian coastline, ME represents the province of Messina, and the second "01" represents the number of one of the 24 PBs studied in this province.

\subsection{Data}

We analyzed four bands of multispectral Sentinel-2B satellite images at a spatial resolution of $10 \mathrm{~m}$ for the land-use mapping of $24 \mathrm{PBs}$ in the coastal municipalities of the province of Messina. Sentinel-2B was placed in orbit on 7 March 2017, together with its twin Sentinel-2A, launched on 23 June 2015; they provide Earth observation data with five days of temporal resolution. Their high spatial resolution of 10, 20, and $60 \mathrm{~m}$ allows crucial information to be obtained on LULC in coastal areas. For each PB in Sicily and the Maltese islands, such information can be obtained every 5 days, allowing regular monitoring of the anthropogenic activities on the enclosed beaches. The Sentinel-2B satellite imagery used in this research (Table 2) was downloaded for free from the SciHub (https://scihub.copernicus.eu/dhus/\#/home) website accessed on 28 May 2020. We downloaded the S2MSI2A product type data-these are level-2 atmospheric corrected satellite images available for the general public. 
Table 2. Sentinel-2 imagery analyzed for land use on PBs of the province of Messina. Three images acquired on 20 October 2019 at 05:50:29 UTC by Sentinel-2B satellite were analyzed for land use/land cover mapping of the PBs located in six municipalities of the province of Messina. These images cover three tiling grids for each municipality with cloud cover percentage varying from 0.43 to 1.88 . Four bands (blue, green, red, and near infrared) with a spatial resolution of $10 \mathrm{~m}$ were used.

\begin{tabular}{ccc}
\hline Municipalities & Sentinel-2 Tiling Grid ID & Cloud Cover (\%) \\
\hline Gioiosa Marea, Lipari, Patti, Malfa & 33SVC & 0.43 \\
\hline Taormina & 33 SWB & 1.65 \\
\hline Milazzo & $33 S W C$ & 1.88 \\
\hline
\end{tabular}

In addition to Sentinel-2B images, very high-resolution Google Earth pro images acquired on 7 July 2019, 1 August 2019, and 23-24 May 2020 and OpenStreetMap (OSM) data were used to conduct photo interpretation and manual digitization.

OSM data are free and open access volunteered geographic information data and are often used in LULC mapping as an additional source of information for mapping and visualization [41,42]. It is advised to use OSM data in conjunction with recognized data, such as sentinel, because OSM still lacks a formal standard.

\subsection{Methodology for Data Processing}

In order to contribute to the current effort aiming for the protection of Mediterranean coastal ecosystems, in general, and their PBs, within BESS Project, the latter has been created to take advantage of the latest land surveillance technology and to implement a management system for specific environmental niches in order to find solutions to manage both Maltese and Sicilian PBs.

The satellite image methodological approach adopted in this study is presented in Figure 2. The flow chart shows the steps followed to extract LULC classes and their accuracy assessment. The methodology can be divided into two steps. The first one concerns data download and preparation; the second step is LULC mapping. As we downloaded atmospherically corrected S2MSI2A products, the first step consisted of elaborating on the layer stacking by combining 4 bands into 1 multispectral image and the selection of training samples for each class (Table 3) available for each PB.

Table 3. Description of classes used for anthropogenic activity mapping on PBs of the province of Messina.

\begin{tabular}{cc}
\hline Classes & Description \\
\hline Shadows & Missing data \\
Built-up & Residential buildings and asphalt surfaces \\
Scattered vegetation & Sparse vegetation with $50 \%$ grassland covering surface \\
Vegetation & Vegetated arable lands or heterogeneous agricultural areas \\
Dense vegetation & Permanent crops, plantation trees, natural or semi-natural forest \\
Bare land & Nonvegetated agricultural and nonagricultural areas \\
Bare land (rocks) & Rocky outcroppings \\
Water & Seawater and swimming pools \\
\hline
\end{tabular}

Both images were processed in the ENvironment for Visualizing Images (ENVI) software, version 5.5 [43]. In addition to LULC, the main linear structures, e.g., streets, were extracted using occurrence-based filtering tools available in ENVI software version 5.5 [44]. Accuracy assessments of LULC classification results were conducted based on validation training samples. The photo interpretation process was carried out by selecting the training sample, whereas the main streets were manually digitized based on OSM data. The results, in percentage, of LULC at $10 \mathrm{~m}$ of spatial resolution within $0.5 \mathrm{~km}$ inland for each PB revealing indirect anthropogenic activities are presented. 


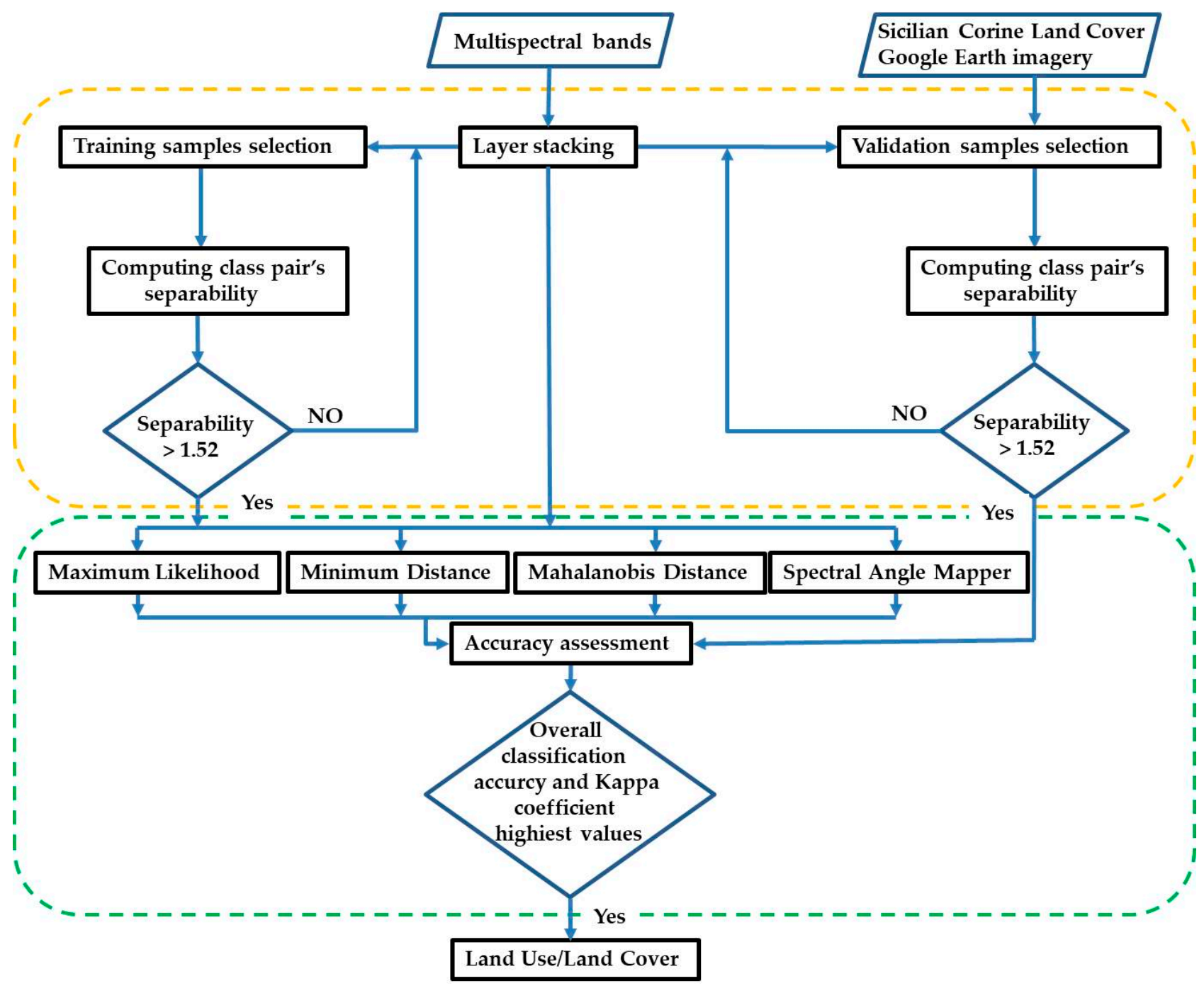

Figure 2. Flowchart of the methodology adopted for land use/land cover (LULC) mapping of PBs located on the coast of Messina province. The class pair separability is the value calculated for the possible combinations of 2 classes available for each $\mathrm{PB}$.

The parameters used to evaluate the quality of LULC results are: (1) the producer's accuracy, which indicates the degree of confidence for correctly classified areas based on the validation of the training samples of a given class; (2) the user's accuracy, which is the percentage of correctly classified areas within all samples classified; (3) the overall accuracy $(\mathrm{OA})$, which is the degree of confidence for the correctly classified areas based on all validation training samples; and (4) the Kappa coefficient, which is the agreement of the classification results with the validation training samples.

\subsection{Training and Validation Samples Collection}

Training and validation samples are the most important input data required for supervised classification of satellite imagery. They determine the number and the names of classes for output results, they allow evaluation of the quality and reliability of classification results, and, last but not least, they are the backbone of any supervised classification work. It is important to ensure that these training and validation samples are sufficient class representatives and cover the whole area of study. In this study, training and validation samples, respectively representing $30 \%$ and $45 \%$ of the studied buffer zone, were manually selected and digitized on Sentinel-2 images, based on photointerpretation [7] by combining 
the same satellite images with very high-resolution Google Earth imagery and Sicilian Corine Land Cover version 2011 mapped at 1:10,000 scales [45,46].

Training and validation samples were collected by selecting and digitizing portions of areas of each LULC class on the Sentinel-2 imagery. The process was performed by comparing the class that we intend to create on Sentinel-2 image with Sicilian Corine Land Cover and Google Earth imagery. As some classes for Sicilian Corine Land Cover would have changed, we preferred to divide them into vegetation, dense vegetation, urban vegetation, and scattered vegetation. Such classes are easily identifiable on Sentinel-2 in its false color near infrared composite image as well as on very high-resolution Google Earth imagery. In addition, we sampled data related to bare land, bare land (rocks), built-up, built up (urban), water, and quarry, which are also noticeable on Sentinel-2 in its false color near infrared composite image. To ensure the quality and accuracy of the output results, the training and validation segments were independently created.

\subsection{Class Pair Separability (Jeffries-Matusita or Transformed Divergence)}

In supervised classification, the training data are used to characterize the classes and to train a predictive model, which is then used to predict land cover in the rest of the image [47]. In order to evaluate the heterogeneity of LULC classes, the separability between two classes was computed. The separability or Jeffries-Matusita distance is an effective metric which evaluates the training samples [48] and measures the quality of how well two classes are distinguished. The separability values range between 0 and 2, with high values indicating better separability, which leads to the precise classification results, while lower values indicate worse separability. For each class pair, we used the value of separability of 1.52 for training and validation samples (Figure 2).

\subsection{Brief Description of the Proposed Image Classification Algorithms}

The analysis of Sentinel-2 imagery for LULC mapping of PBs was conducted by using 4 classification algorithms.

\subsubsection{Maximum Likelihood Classification}

The maximum likelihood classifier is a supervised classification method available in different geographic information system software, such as ArcGIS, ENVI, and Erdas Imagine. In our study, we used the maximum likelihood algorithm available in ENVI version 5.5. Maximum likelihood is commonly used for LULC [49] mapping using Sentinel2 satellite image analysis [50]. During satellite image processing, each pixel is assigned to the class with the highest likelihood. This assignment depends on a threshold value set by the user-in our case, the value threshold was lower, and thus some pixels were unclassified. More details about the maximum likelihood classifier are presented by Ahmad and Quegan [51].

\subsubsection{Minimum Distance Classification}

The minimum distance classifier available in the ENVI software is a supervised classification algorithm which uses the mean of a region of interest's shapefiles for each class and calculates the Euclidean distance from each unknown pixel to the mean region of interest of each class [52,53]. In our study, no distance threshold value was specified, which allowed us to perform the classification of the pixels of input data to the nearest class. The classification was conducted in ENVI software version 5.5.

\subsubsection{Mahalanobis Distance}

The Mahalanobis distance is a direction-sensitive distance classifier. It uses statistics for each class of input data. Mahalanobis distance is similar to the maximum likelihood classification, but it assumes that all class covariances are equal, and therefore, it is a faster method [52]. During the processing in the ENVI software, no specific distance threshold 
value was used, and this allowed the algorithm to classify all the pixels to the closest training data.

\subsubsection{Spectral Angle Mapper}

The spectral angle mapper is a physically based spectral classification that uses an $n$ - (number of spectral bands) dimensional angle to match pixels to training data. It is a supervised classification machine learning method that is used to determine the spectral similarity between two spectra (a given spectra image and reference spectra) by calculating the angle between the spectra and treating them as regions of interest in a dimensional space equal to the number of bands $[54,55]$. The pixels are classified to the classes of the smallest angle between the training mean region of interest and each pixel region of interest in n-dimensional space. The classification was performed in ENVI software version 5.5 with reflectance data calibrated to the shapefile of the area of interest, which allowed us to perform a classification relatively insensitive to illumination and albedo effects.

\subsection{Occurrence-Based Filtering}

We applied texture filtering to the Sentinel-2B imagery using an occurrence-based filter available in ENVI software version 5.5. For more than three decades, texture has been of great interest to remote sensing analysts [56]. For each pixel, texture analysis generates spatial variability measurements, which produce data that is easily classifiable at the pixel level [55]. This information helps to identify linear structures composed of contiguous pixels with the same tone values. The first-order occurrence of measured textures, namely mean and variance, were computed. This allowed for the distinction of streets and roads from other LULC classes by measuring the distribution of gray tones around the mean (Figure 3). The measure of mean and the variance were computed with $3 \times 3$ kernels as follows (Equations (1) and (2)) [57]:

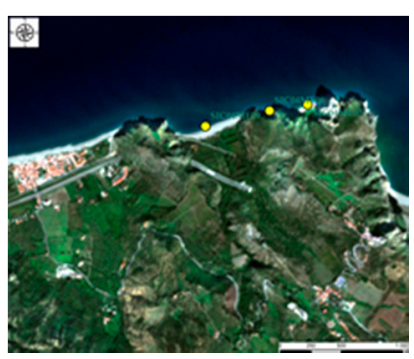

(a)

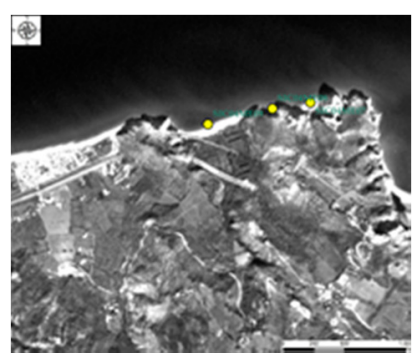

(b)

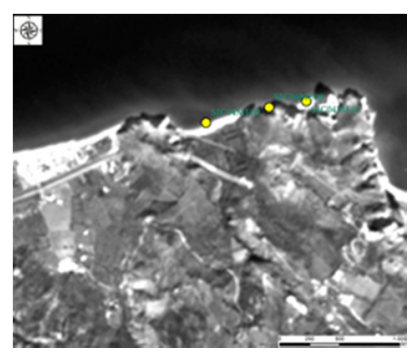

(c)

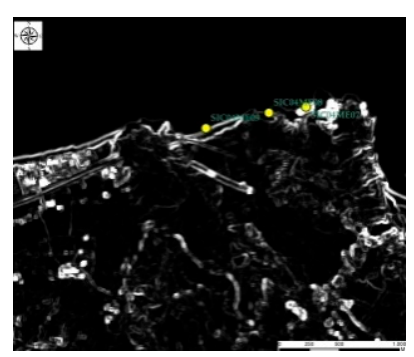

(d)

Figure 3. Sentinel-2 natural color composite image: (a) green band; (b) mean; (c) variance; (d) gray tone computed in the ENVI software with $3 \times 3$ kernel.

Mean:

$$
\begin{array}{ll} 
& M=\Sigma_{i} \Sigma_{j} X(i, j) \\
\text { Variance : } \quad & V=\Sigma_{i} \Sigma_{j}(i-M)^{2} X(i, j)
\end{array}
$$

where $M$ is the mean, $V$ is the variance, $i$ is gray tone, and $X$ is a matrix of gray tone of the image.

The results of the occurrence-based filter were then compared with OSM data to identify and digitize the main street in a $500 \mathrm{~m}$ buffer zone from the PB. The process followed a photo-interpretation process which allowed us to classify and manually digitize the streets. 


\section{Results}

The results obtained show that Sentinel-2 imagery provides useful LULC information that could also be used to evaluate and better understand the impact of anthropogenic activities in small coastal ecosystems.

In our study, we focused on these 24 PBs (Table 4) because they seemed to be a good representation of Mediterranean PBs located in different coastal situations; otherwise, similar results have also been obtained for the other 132 PBs investigated within the BESS Project.

Table 4. Descriptions of 24 PBs of the province of Messina.

\begin{tabular}{ccccc}
\hline Name of the Beaches & Municipality/Island & Codes of the Beaches & $\begin{array}{c}\text { Coordinates (Decimal Degrees) } \\
\text { Latitudes }\end{array}$ & 15.297601 \\
South Isola Bella & Taormina & SIC01ME01 & 37.850035 & 15.300546 \\
North Isola Bella & Taormina & SIC01ME02 & 37.852593 & 15.301613 \\
Mazzarò & Taormina & SIC02ME03 & 37.855315 & 15.243056 \\
East Milazzo & Milazzo & SIC03ME04 & 38.263882 & 15.237303 \\
North Milazzo & Milazzo & SIC03ME05 & 38.269745 & 15.236534 \\
West Milazzo & Milazzo & SIC03ME06 & 38.264215 & 15.040707 \\
East Tindari & Patti & SIC04ME07 & 38.151473 & 15.037139 \\
Central Tindari & Patti & SIC04ME08 & 38.151205 & 15.03108 \\
West Tindari & Patti & SIC04ME09 & 38.150371 & 14.920996 \\
East Capo Calavà & Gioiosa Marea & SIC05ME10 & 38.190424 & 14.910634 \\
West Capo Calavà & Gioiosa Marea & SIC06ME11 & 38.188102 & 14.998676 \\
Punta dell'Asino & Lipari/Vulcano & SIC07ME12 & 38.370453 & 15.003052 \\
Punta Bandiera & Lipari/Vulcano & SIC08ME13 & 38.373471 & 14.960705 \\
La Forbice & Lipari/Lipari & SIC09ME14 & 38.450786 & 14.972756 \\
Pignataro di Fuori & Lipari/Lipari & SIC10ME15 & 38.477989 & 14.961744 \\
Sabbie Bianche & Lipari/Lipari & SIC11ME16 & 38.498898 & 14.962953 \\
Lido Blu & Lipari/Lipari & SIC12ME17 & 38.501816 & 14.834378 \\
Punta Scario & Malfa/Salina & SIC13ME18 & 38.582392 & 14.807179 \\
Pollara & Malfa/Salina & SIC14ME19 & 38.580203 & 15.065786 \\
Zimmaro & Lipari/Panarea & SIC15ME20 & 38.628785 & 15.061491 \\
West Preistorico & Lipari/Panarea & SIC16ME21 & 38.625762 & 15.063061 \\
Central Preistorico & Lipari/Panarea & SIC16ME22 & 38.62564 & 38.625176 \\
East Preistorico & Lipari/Panarea & SIC16ME23 & 38.555222 & \\
Le Punte & Lipari/Filicudi & SIC17ME24 & &
\end{tabular}

The results obtained from the multispectral Sentinel-2B satellite image analysis are presented in maps and tables. The maps represent the location of LULC classes for the main Island of Sicily (Figure 4) and for the minor Islands of the Aeolian Archipelago (Figure 5), whereas the table contains statistical analysis and accuracy assessment results (Table 5). The results cover 24 PBs located in six coastal municipalities of the Messina province, including classification maps and statistical parameters, and the quality and extent of classes. We noticed that in the $500 \mathrm{~m}$ buffer zone of the PBs, information on the biophysical parameters, namely surface cover fractions, can be obtained by conducting LULC mapping on Sentinel-2 images. For most of the PBs, a large area is occupied by vegetation, built-up areas, and bare land. For each $\mathrm{PB}$, more detailed descriptions are presented in the Supplementary Material (Figures S1-S12 and Tables S1-S12). Information on the biophysical parameters represented by the surface cover fraction indicates the main anthropogenic activity conducted in nearby each PB. 


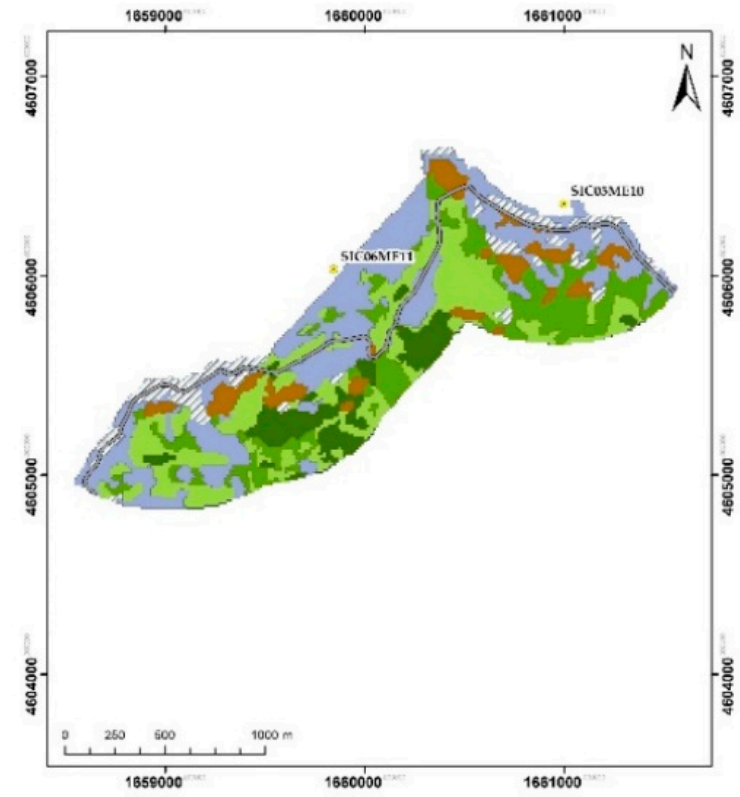

(a)

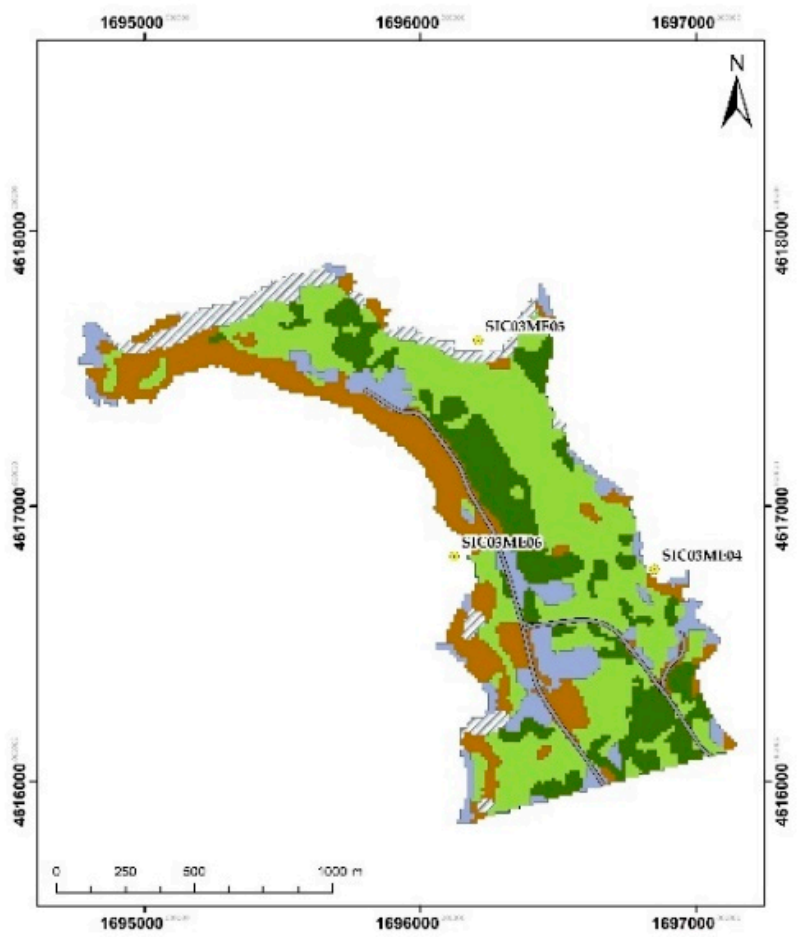

(c)

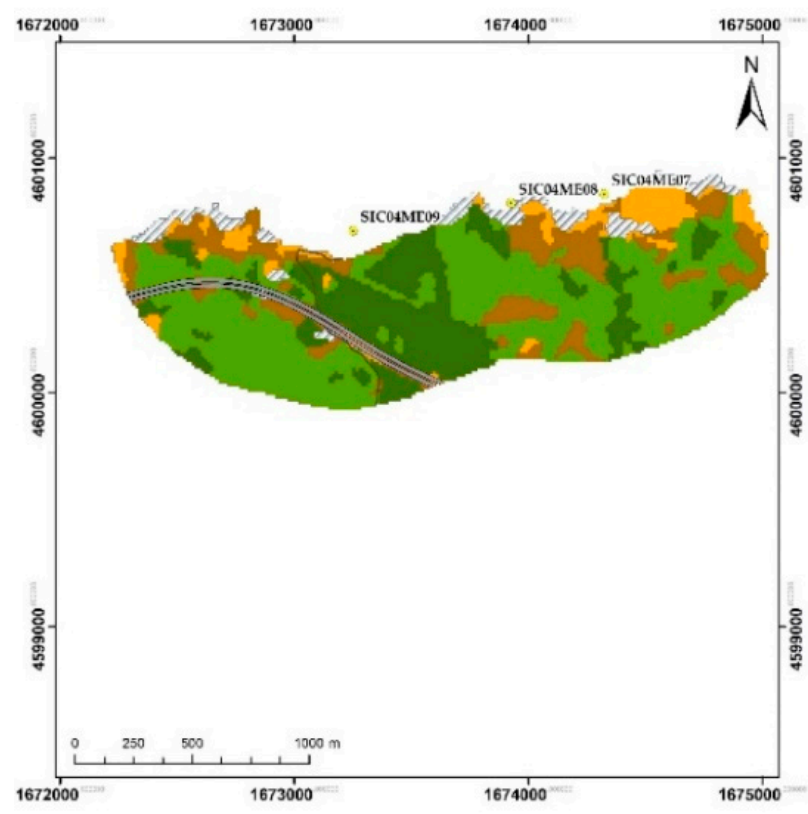

(b)

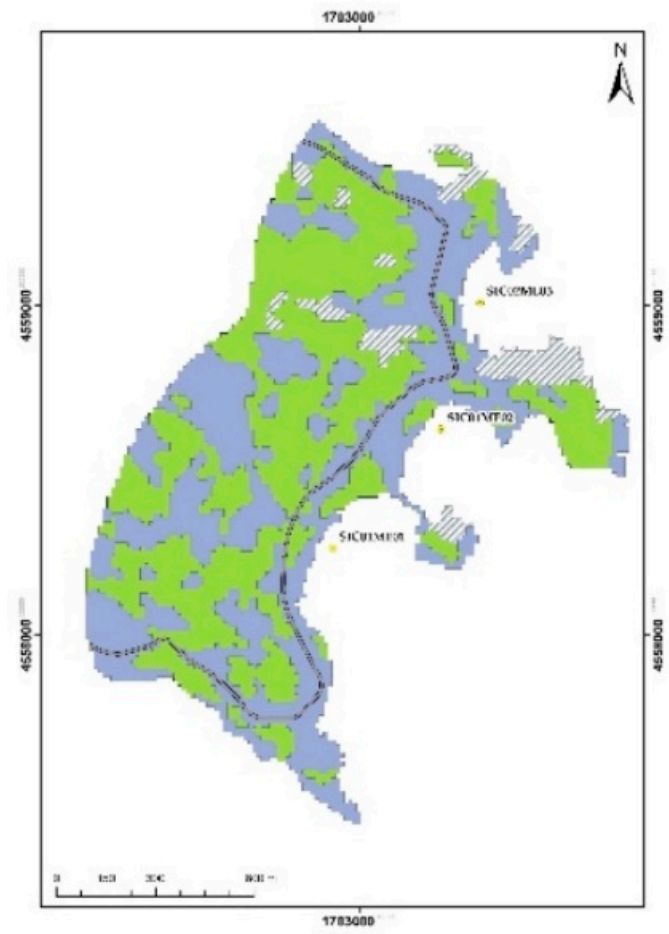

(d)

Legend

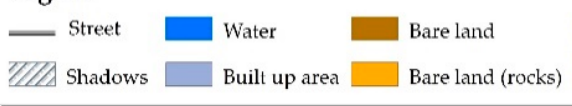

Dense vegetation $\quad \mid$ Vegetation

Scattered vegetation

Figure 4. Land use/land cover classification results for the PBs of Sicily, the main island, clockwise from top left: East Capo Calavà (SIC05ME10) and West Capo Calavà (SIC06ME11) (a); Patt-Tindari's PBs East (SIC04ME07), Center (SIC04ME08), and West (SIC04ME09) (b); Milazzo's PBs East (SIC03ME04), North (SIC03ME05), and West (SIC03ME06) (c); South Isola Bella (SIC01ME01), North Isola Bella (SIC01ME02), and Mazzarò (SIC02ME03) (d). 


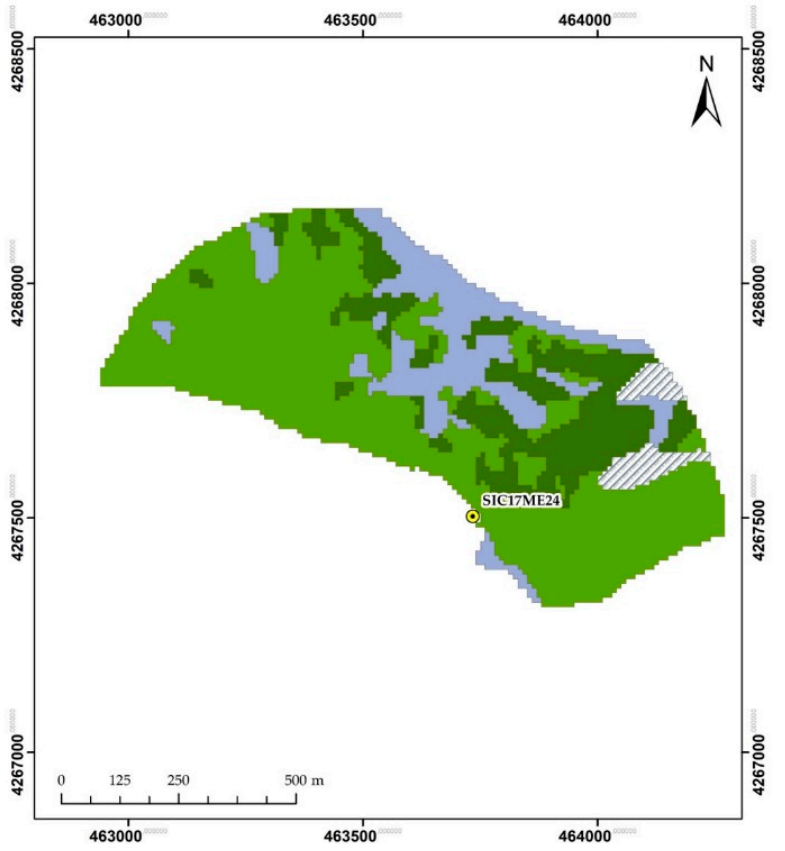

(a)

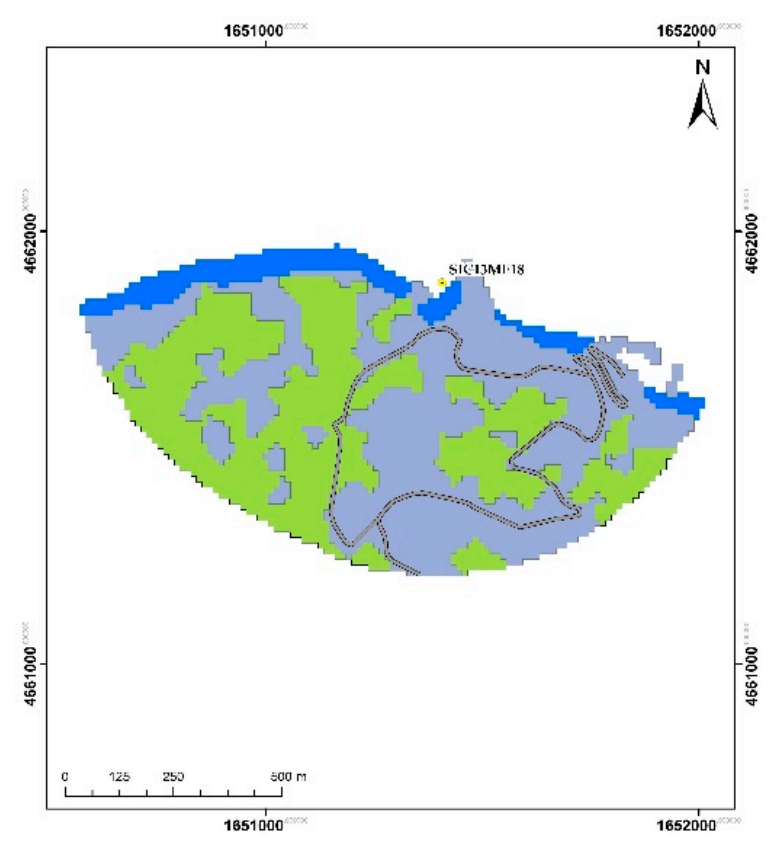

(c)

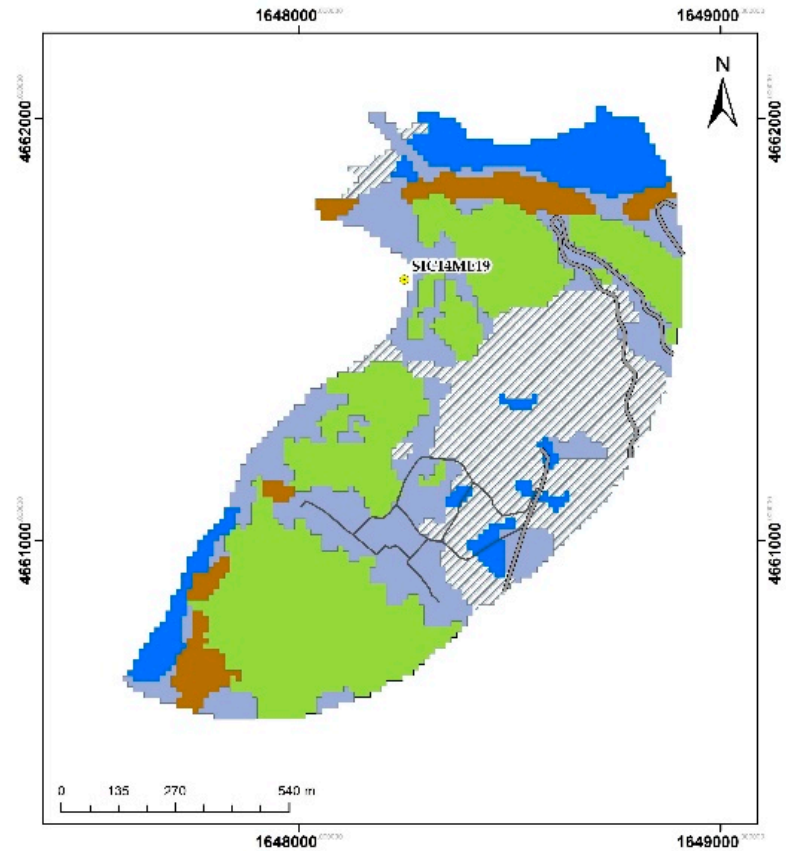

(b)

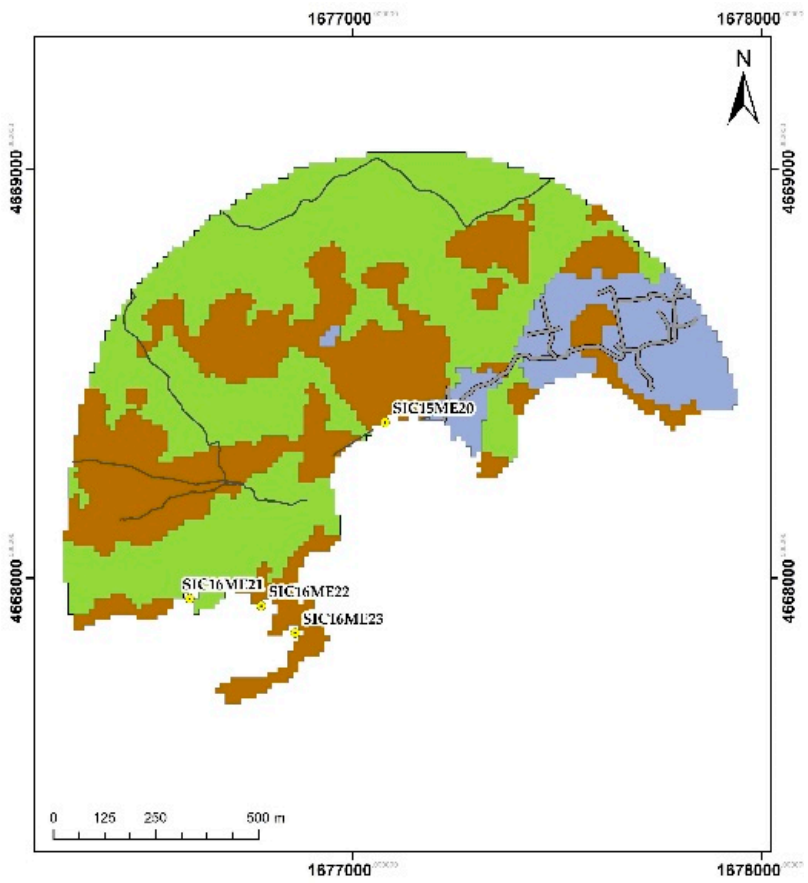

(d)

Figure 5. Cont. 


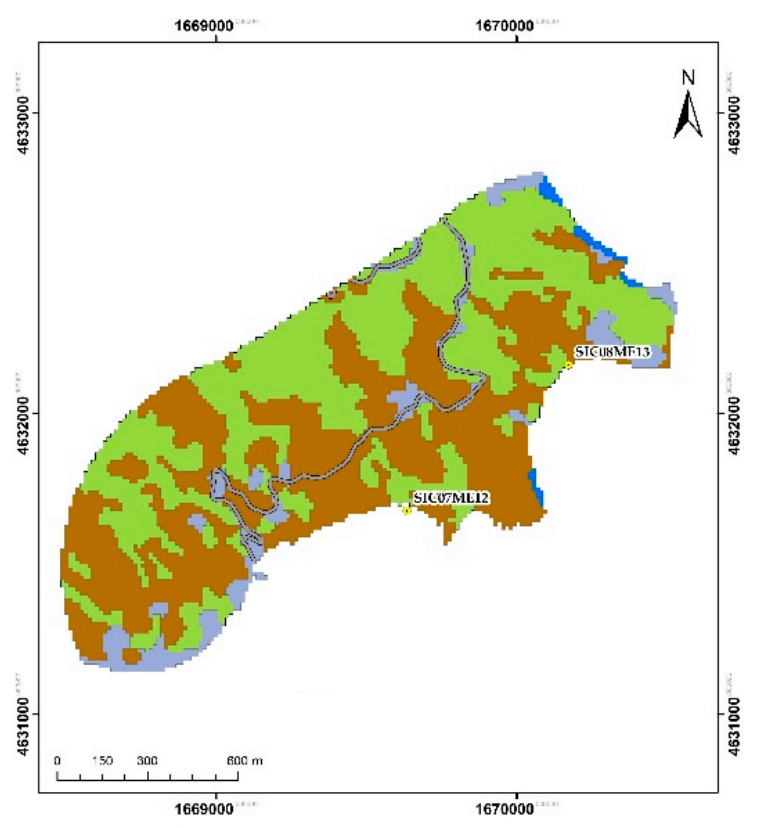

(e)

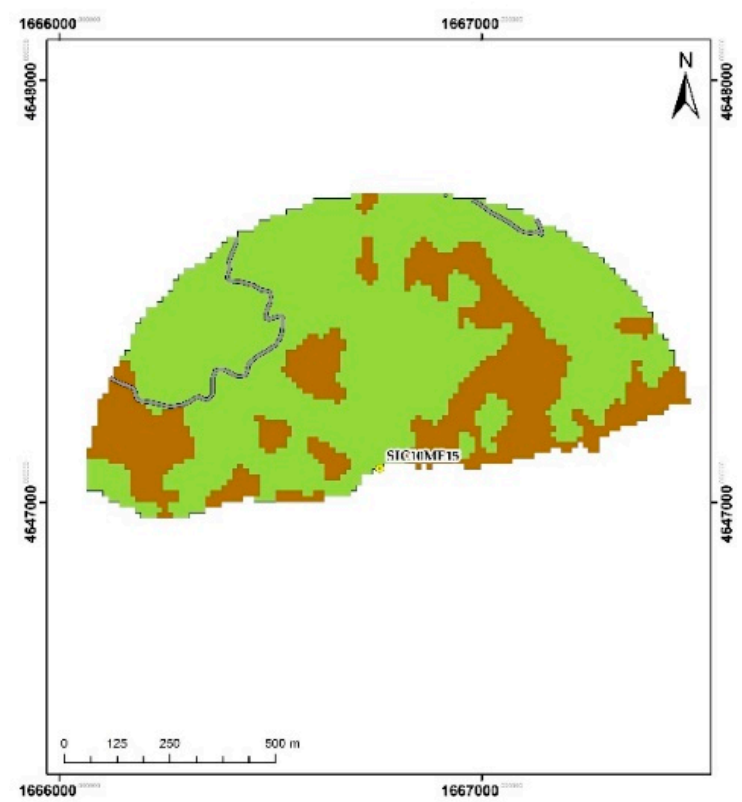

(g)

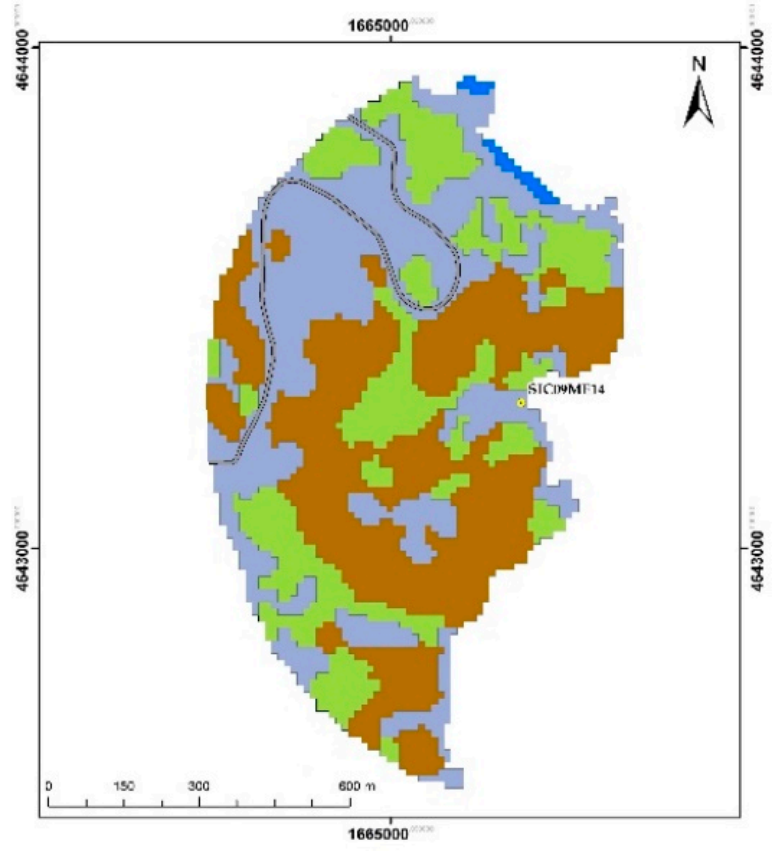

(f)

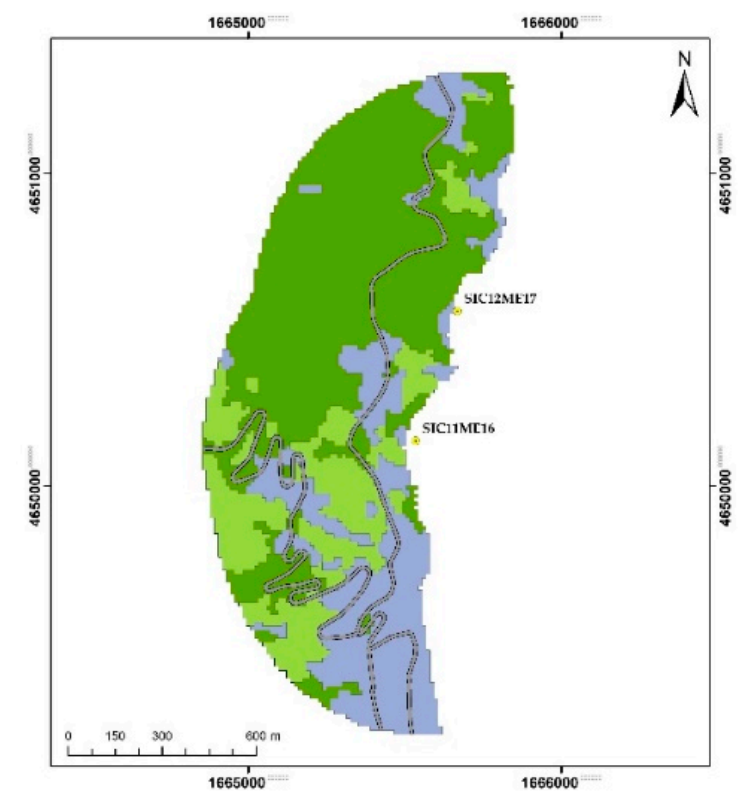

(h)

\begin{tabular}{|c|c|c|c|c|}
\hline \\
\hline ב Street & \multicolumn{4}{|c|}{ Legend } \\
\hline TDDA Shadows & Built up area & Bare land (rocks) & Scattered vegetation & \\
\hline
\end{tabular}

Figure 5. Land use/land cover classification results for the PBs of the Aeolian Archipelago, clockwise from top left: Filicudi-Le Punte (SIC17ME24) (a); Salina-Pollara (SIC14ME19) (b); Salina-Punta Scario (SIC13ME18) (c); Zimmaro (SIC15ME20), West Preistorico (SIC16ME21), Central Preistorico (SIC16ME22), and East Preistorico (SIC16ME23) (d); Volcano Island-Punta dell'Asino (SIC07ME12) and Volcano Island-Punta Bandiera (SIC08ME13) (e); Lipari-La Forbice (SIC09ME14) (f); Lipari-Pignataro di Fuori (SIC10ME15) (g); Lipari-Sabbie Bianche (SIC11ME16) and Lipari-Lido Blu (SIC12ME17) (h). 
Table 5. Overall land use/land cover classification results and analysis obtained for the PBs located on the coast of Messina province.

\begin{tabular}{|c|c|c|c|c|c|c|c|}
\hline \multirow{2}{*}{$\begin{array}{c}\text { Codes of the } \\
\text { PBs }\end{array}$} & \multirow{2}{*}{ Classes } & \multicolumn{2}{|c|}{ Area } & \multirow{2}{*}{$\begin{array}{c}\text { Producer's } \\
\text { Accuracy (\%) }\end{array}$} & \multirow{2}{*}{$\begin{array}{c}\text { User's } \\
\text { Accuracy (\%) }\end{array}$} & \multirow{2}{*}{$\begin{array}{l}\text { Overall Clas- } \\
\text { sification } \\
\text { Accuracy }(\%)\end{array}$} & \multirow{2}{*}{$\begin{array}{c}\text { Kappa } \\
\text { Coefficient }\end{array}$} \\
\hline & & $\mathrm{m}^{2}$ & $(\%)$ & & & & \\
\hline \multirow{3}{*}{$\begin{array}{l}\text { SIC01ME01, } \\
\text { SIC01ME02, } \\
\text { SIC02ME03 }\end{array}$} & Shadows & 53,700 & 6.05 & 100 & 27.78 & \multirow{3}{*}{96.98} & \multirow{3}{*}{0.93} \\
\hline & Built-up & 426,100 & 48 & 100 & 98.62 & & \\
\hline & Vegetation & 407,800 & 45.94 & 95.70 & 100 & & \\
\hline \multirow{5}{*}{$\begin{array}{l}\text { SIC03ME04, } \\
\text { SIC03ME05, } \\
\text { SIC03ME06 }\end{array}$} & Shadows & 61,500 & 6.27 & 100 & 76.47 & \multirow{5}{*}{89.07} & \multirow{5}{*}{0.85} \\
\hline & Built-up & 119,600 & 12.21 & 86.36 & 96.94 & & \\
\hline & Vegetation & 399,700 & 40.8 & 96.35 & 84.62 & & \\
\hline & Dense vegetation & 189,400 & 19.33 & 81.48 & 97.06 & & \\
\hline & Bare land & 209,300 & 21.36 & 95.12 & 75.00 & & \\
\hline \multirow{5}{*}{$\begin{array}{l}\text { SIC04ME07, } \\
\text { SIC04ME08, } \\
\text { SIC04ME09 }\end{array}$} & Shadows & 59,600 & 5.45 & 56.1 & 96.72 & \multirow{5}{*}{87.06} & \multirow{5}{*}{0.79} \\
\hline & Scattered vegetation & 496,200 & 45.42 & 91.01 & 93.08 & & \\
\hline & Dense vegetation & 256,600 & 23.49 & 99.32 & 82.21 & & \\
\hline & Bare land & 184,500 & 16.89 & 68.25 & 89.84 & & \\
\hline & Bare land (rocks) & 95,400 & 8.73 & 83.56 & 46.56 & & \\
\hline \multirow{6}{*}{$\begin{array}{l}\text { SIC05ME10, } \\
\text { SIC06ME11 }\end{array}$} & Shadows & 94,100 & 7.37 & 98.08 & 100 & \multirow{6}{*}{89.63} & \multirow{6}{*}{0.86} \\
\hline & Built-up & 428,800 & 33.62 & 92.24 & 99.55 & & \\
\hline & Scattered vegetation & 214,200 & 16.79 & 74.71 & 65.33 & & \\
\hline & Vegetation & 322,000 & 25.24 & 88.10 & 81.70 & & \\
\hline & Dense vegetation & 112,700 & 8.83 & 89.39 & 100 & & \\
\hline & Bare land & 103,500 & 8.11 & 100 & 98.54 & & \\
\hline \multirow{4}{*}{ SIC09ME14 } & Built-up & 167,100 & 36.64 & 92.83 & 89.80 & \multirow{4}{*}{92.63} & \\
\hline & Vegetation & 111,600 & 24.47 & 95.73 & 94.58 & & \\
\hline & Bare land & 173,500 & 38.04 & 94.32 & 93.79 & & 0.89 \\
\hline & Water & 3800 & 0.83 & 67.65 & 100 & & \\
\hline & Vegetation & 333,800 & 71.93 & 100 & 83.55 & & \\
\hline SIC10ME15 & Bare land & 130,200 & 28.06 & 92.96 & 100 & 94.81 & 0.87 \\
\hline & Built-up & 7088 & 26.77 & 97.74 & 98.30 & & \\
\hline SIC11ME16, & Scattered vegetation & 424,400 & 53.44 & 99.15 & 99.09 & 98.76 & 0.97 \\
\hline & Vegetation & 157,100 & 19.78 & 100 & 97.17 & & \\
\hline & Built-up & 82,400 & 8.58 & 82.83 & 93.18 & & \\
\hline SIC07ME12, & Vegetation & 421,900 & 43.93 & 97.51 & 99.49 & & \\
\hline SIC08ME1 & Bare land & 448,400 & 46.69 & 100 & 94.67 & 96.08 & 0.93 \\
\hline & Water & 7600 & 0.79 & 66.67 & 100 & & \\
\hline SIC15ME20, & Built-up & 83,500 & 12.44 & 98.42 & 95.04 & & \\
\hline SIC16ME21, & Vegetation & 350,200 & 52.21 & 98.31 & 84.30 & 92.80 & 0.88 \\
\hline SIC16ME22 & Bare land & 237,000 & 35.33 & 86.44 & 99.14 & & \\
\hline & Shadows & 19,800 & 3.47 & 98.63 & 100 & & \\
\hline & Built-up & 99,000 & 17.35 & 94.59 & 100 & & \\
\hline SIC17ME24 & Scattered vegetation & 338,600 & 59.35 & 87.84 & 98.26 & 90.45 & 0.82 \\
\hline & Dense vegetation & 113,100 & 19.82 & 95.06 & 70 & & \\
\hline & Built-up & 226,800 & 51.53 & 96.99 & 99.56 & & \\
\hline SIC13ME18 & Vegetation & 176,900 & 40.19 & 100 & 92 & 97.76 & 0.95 \\
\hline & Water & 36,400 & 8.27 & 97.97 & 99.32 & & \\
\hline & Shadows & 153,400 & 23.92 & 97.40 & 100 & & \\
\hline & Built-up & 158,500 & 24.71 & 92.48 & 72.32 & & \\
\hline SIC14ME19 & Vegetation & 223,400 & 34.84 & 99.08 & 98.19 & 94.89 & 0.92 \\
\hline & Bare land & 38,700 & 6.03 & 63.43 & 96.52 & & \\
\hline & Water & 67,200 & 10.48 & 100 & 95.63 & & \\
\hline
\end{tabular}




\section{Discussion}

Currently, open available geospatial data are being used for land use/land cover (LULC) change analysis of coastal areas [6,30-32]. In this study, we conducted a LULC mapping analysis of the PBs located on the coast of Messina province. The area of study was chosen in order to evaluate if the adopted approach would be an adequate study model for other different PBs. Our research methodology evaluates four classification methods with the aim of determining which one could be used for an accurate LULC mapping of the PBs. Within a buffer zone of $500 \mathrm{~m}$ from the shoreline, samples representing the main land cover classes of the PBs were selected and extracted from Sentinel-2 imagery. They were used during image classification procedures and eventually for extracting information on the biophysical parameters, namely surface cover fractions. For most of the PBs, a large area is occupied by vegetation, built-up areas, and bare land. The identification of surface cover fractions indicates the anthropogenic activity conducted nearby each PB.

\subsection{Effect of Class Combination and Topography on Classification Accuracy and Precision}

An evaluation of the effect of class combination and topography on the classification accuracy and precision was performed. For each $\mathrm{PB}$, the class pair separability was computed. Separability values indicate how LULC classes can be distinguished on satellite images. The values of separability of two combined classes vary between 0 and 2, with higher values indicating the best separability of classes leading to more precise classification results. The area of study presents topographic variations resulting in shadows near the cliffs or hill slopes. An interesting issue is the presence of the shadows. Some images may have surfaces that are not immediately detectable, which are classified as shadows. In most of the images analyzed, the percentage of shadow is less than $8 \%$; in six images, it is practically absent; and in the last image, it reaches almost $24 \%$. When the images are taken at the same time, the issue of the shadows could be resolved by integrating freely available multitemporal satellite images with moderate spatial resolution, such as those from the Landsat program. In any case, the separability of different LULC features was guaranteed, and it was taken into account in the application of classification methods. These shadows reduce the separability of LULC classes, eventually reducing the precision of the results. In this study, we used the value of separability of 1.52 for training and validation samples.

Figure 6 shows the difference between the performances of the four different classification methods evaluated. For each method, overall classification accuracy and kappa coefficient are presented. We noticed that MaL performs better than MiD, MaD, and SAM classifiers; however, for the classification of only two classes, SAM performs better than other classifiers. We noticed that the range of overall classification accuracy is predicted by the number of classes as well as the values of the class pair separability. For a small number of classes and a high value of separability, the MaL classifier demonstrates the best ability for mapping. However, for only two LULC classes, the SAM classifier performs better with high overall classification accuracy and kappa coefficient values, due to the smallest angle between the classes and spectral bands.

\subsection{Limitation and Suitability of Conducting Supervised Classification Procedures}

Phiri et al. [58] reviewed the contribution of Sentinel-2 to land cover/use classification and noticed that Sentinel-2 has a positive impact on land cover/use monitoring, specifically in the monitoring of crops, forests, urban areas, and water resources; $\mathrm{Xu}$ et al. [59] used Sentinel-2 multispectral imagery to extract a high-precision urban impervious surface. In our case study, we noticed that for LULC mapping activities conducted on a small area, the ability to differentiate all land cover objects is limited by spatial resolution and the presence of missing data pixels in mountainous landscapes. The results of the current study demonstrate that information on the biophysical parameters, namely surface cover fractions, of the coastal area can be obtained by conducting LULC mapping on Sentinel-2 images. The proposed approach contributes to coastal research studies, especially research on the LULC of PBs. We demonstrate that the supervised classification procedures rely mainly 
on three components, namely classifier algorithms, training and validation samples, and dataset imagery. While recent improvements have been made to machine learning classifier algorithms and several datasets of imagery are available, more effort should be made for the collection and the preparation of training and validation samples.

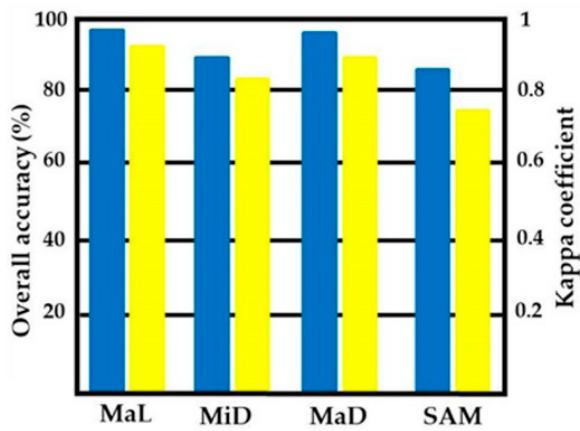

(a)

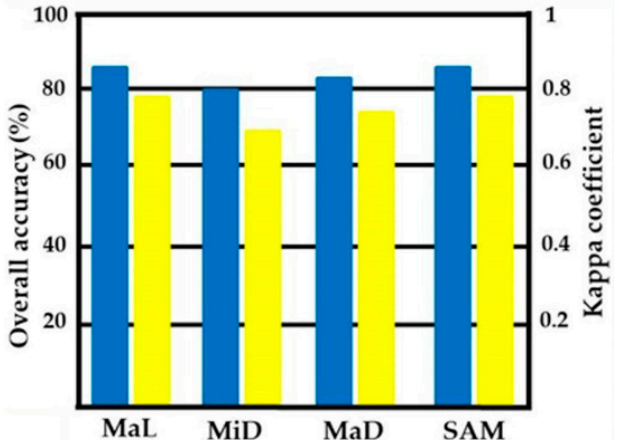

(c)

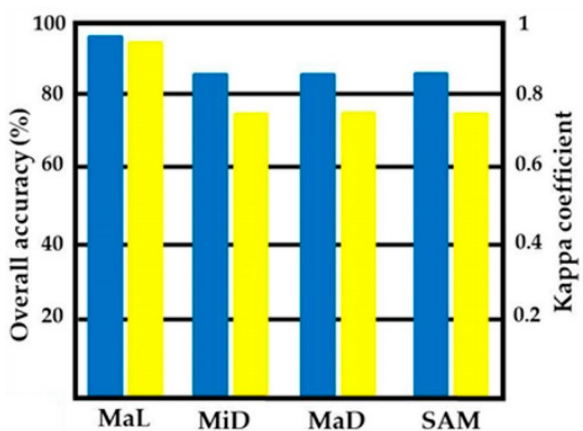

(e)

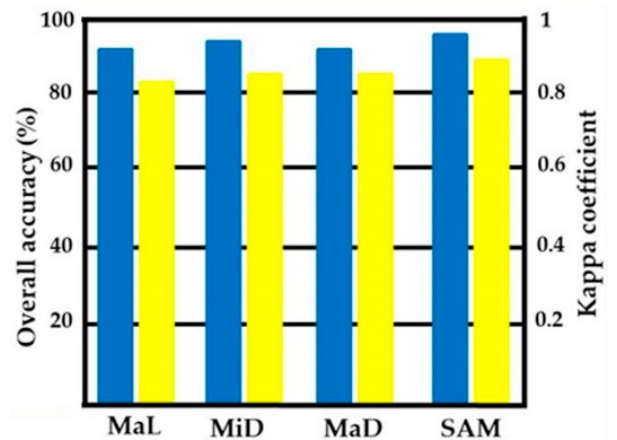

(g)

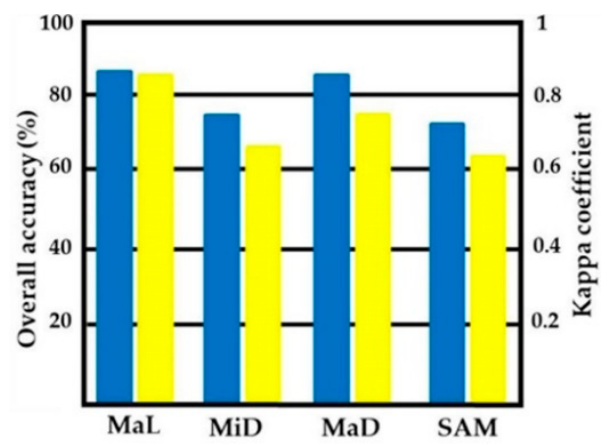

(b)

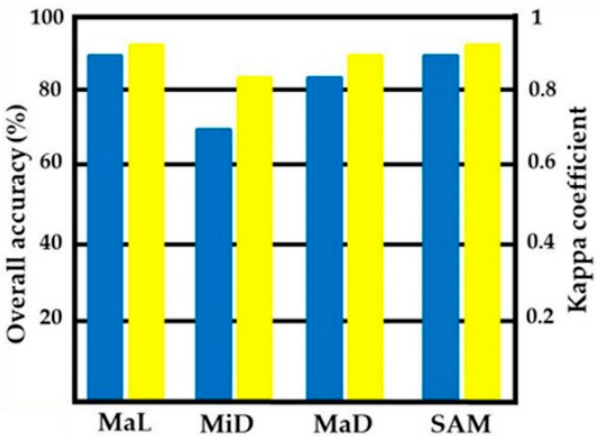

(d)

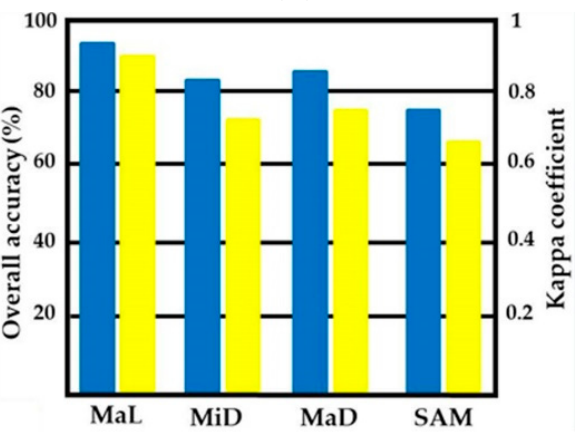

(f)

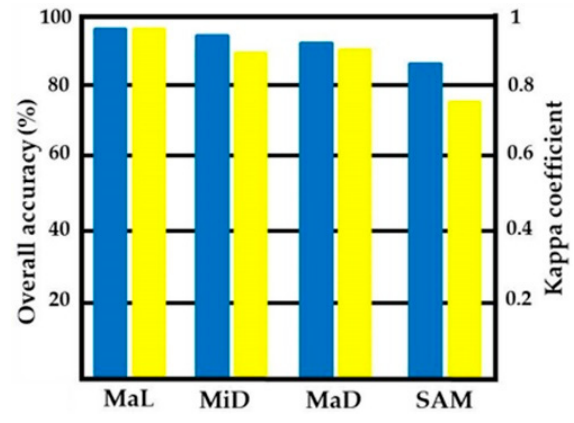

(h)

Figure 6. Cont. 


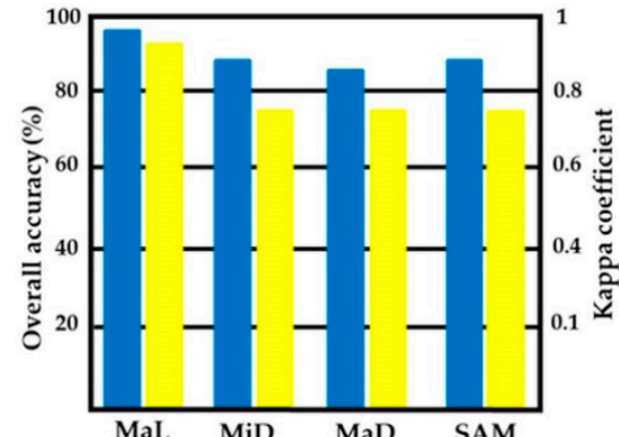

(i)

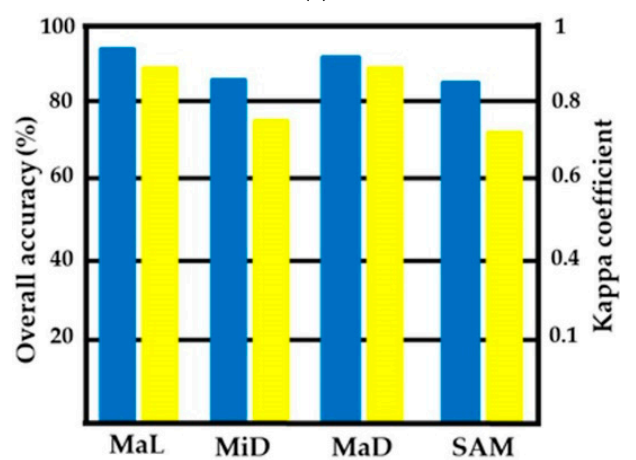

(k)

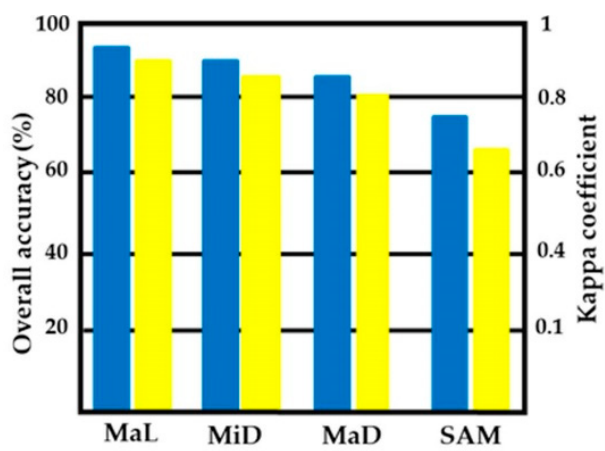

(j)

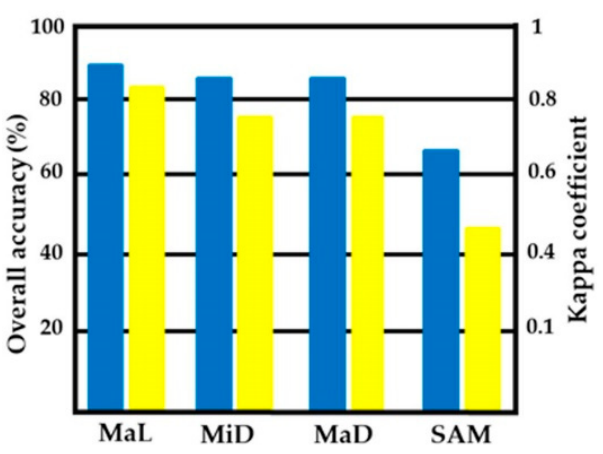

(1)

Overall accuracy $(\%)$

Kappa coefficient

Figure 6. Performance of maximum likelihood (MaL), minimum distance (MiD), mahalanobis distance $(\mathrm{MaD})$ and spectral angle mapper (SAM) classification methods for the PBs of Messina province, with OA and kappa coefficient for South Isola Bella (SIC01ME01), North Isola Bella (SIC01ME02), and Mazzarò (SIC02ME03) PBs located on the coast of Taormina (a); OA and kappa coefficient for three PBs of East (SIC03ME04), North (SIC03ME05), and West (SIC03ME06) located along the coast of Milazzo (b); OA and kappa coefficient for the Patti-Tindari's PBs East (SIC04ME07), Center (SIC04ME08), and West (SIC04ME09) (c); OA and kappa coefficient for the two PBs of East Capo Calavà (SIC05ME10) and West Capo Calavà (SIC06ME11) on the coast of Gioiosa Marea (d); OA and kappa coefficient for the PB of Lipari-La Forbice (SIC09ME14) (e); OA and kappa coefficient for the PB of Lipari-Pignataro di Fuori (SIC10ME15) (f); OA and kappa coefficient for the two PBs of Lipari-Sabbie Bianche (SIC11ME16) and Lipari-Lido Blu (SIC12ME17) located on the east coast of Lipari (g); OA and kappa coefficient for the two PBs of Volcano Island, Punta dell'Asino (SIC07ME12) and Punta Bandiera (SIC08ME13) (h); OA and kappa coefficient for four PBs of Zimmaro (SIC15ME20), West Preistorico (SIC16ME21), and Central Preistorico (SIC16ME22) of Panarea Island (i); OA and kappa coefficient for one PB of Filicudi-Le Punte (SIC17ME24) (j); OA and kappa coefficient for one PB of Punta Scario (SIC13ME18) located on the coast of Malfa on Salina Island (k); and OA and kappa coefficient for one PB of Pollara (SIC14ME19) located on the coast of Malfa (1).

\section{Conclusions}

In this study, satellite images of Sentinel-2B were processed for LULC mapping of the PBs located on the coast of Messina province. The area of study was chosen in order to evaluate if the adopted approach would be an adequate study model for other different PBs. The obtained maps of the LULC allowed us to determine the location of different anthropogenic activities conducted near the PBs. They are essentially dominated by agriculture and forestry. The construction activities dominating built-up areas and urban areas represent the second most prevalent human activities. Considering the applied methodology, information on the biophysical parameters, namely surface cover fractions, 
can be retrieved from Sentinel-2 images. Indeed, due to the global coverage of Sentinel-2, its images can be used for the LULC mapping of other PBs. Such information will effectively improve the monitoring of coastal areas.

Supplementary Materials: The following are available online at https:/ /www.mdpi.com/article/10 .3390/land10070678/s1, Detailed descriptions of Figure S1: Sentinel-2 natural color composite image of Taormina: (a) showing two PBs of Isola Bella (SIC01ME01 and SIC01ME02) and one in Mazzarò Bay (SIC02ME03) and (b) the land use/land cover classification result, Table S1: Land use/land cover classification results of South Isola Bella (SIC01ME01), North Isola Bella (SIC01ME02), and Mazzarò (SIC02ME03) PBs and accuracy assessment (Taormina); Figure S2: Sentinel-2 natural color composite image of Milazzo: (a) showing three PBs of East (SIC03ME04), North (SIC03ME05), and West (SIC03ME06) located along the coast of the Marine Protected Area and (b) the land use/land cover classification result, Table S2: Land use/land cover classification results of Milazzo's PBs East (SIC03ME04), North (SIC03ME05), and West (SIC03ME06) and accuracy assessment; Figure S3: Sentinel-2 natural color composite image of Patti: (a) showing three of Tindari's PBs from East (SIC04ME07), Center (SIC04ME08), and West (SIC04ME09) located along the rocky promontory of the homonymous cape and (b) the land use/land cover classification result, Table S3: Land use/land cover classification results of the Patt-Tindari's PBs East (SIC04ME07), Center (SIC04ME08), and West (SIC04ME09) and accuracy assessment; Figure S4: Sentinel-2 natural color composite image of Gioiosa Marea: (a) showing the two PBs of East Capo Calavà (SIC05ME10) and West Capo Calavà (SIC06ME11) and (b) the land use/land cover classification result, Table S4: Land use/land cover classification results of East Capo Calavà (SIC05ME10) and West Capo Calavà (SIC06ME11) PBs and accuracy assessment (Gioiosa Marea); Figure S5: Sentinel-2 natural color composite image (a) showing the PB of Lipari-La Forbice (SIC09ME14) located on the east coast of the island and (b) the land use/land cover classification result, Table S5: Land use/land cover classification results of Lipari-La Forbice (SIC09ME14) PB and accuracy assessment; Figure S6: Sentinel-2 natural color composite image (a) showing the PB of Lipari-Pignataro di Fuori (SIC10ME15) located on the south coast of the island and (b) the land use/land cover classification result, Table S6: Land use/land cover classification results of Lipari-Pignataro di Fuori (SIC10ME15) pocket beach and accuracy assessment; Figure S7: Sentinel-2 natural color composite image (a) showing the two PBs of LipariSabbie Bianche (SIC11ME16) and Lipari-Lido Blu (SIC12ME17) located on the east coast of Lipari and (b) the land use/land cover classification result, Table S7: Land use/land cover classification results of Lipari-Sabbie Bianche (SIC11ME16) and Lipari-Lido Blu (SIC12ME17) pocket beaches and accuracy assessment (next); Figure S8: Sentinel-2 natural color composite image of Volcano Island (Lipari): (a) showing the two PBs of Volcano Island: Punta dell'Asino (SIC07ME12) and Punta Bandiera (SIC08ME13) and (b) the land use/land cover classification result, Table S8: Land use/land cover classification results of Volcano Island-Punta dell'Asino (SIC07ME12) and Volcano Island-Punta Bandiera (SIC08ME13) PBs and accuracy assessment; Figure S9: Sentinel-2 natural color composite image of Panarea Island (Lipari): (a) showing four PBs of Zimmaro (SIC15ME20), West Preistorico (SIC16ME21), Central Preistorico (SIC16ME22), and East Preistorico (SIC16ME23) and (b) the land use/land cover classification results, Table S9: Land use/land cover classification results of Zimmaro(SIC15ME20), West Preistorico (SIC16ME21), Central Preistorico (SIC16ME22), and East Preistorico (SIC16ME23) pocket beaches and accuracy assessment (Panarea Island-Lipari); Figure S10: Sentinel-2 natural color composite image of Filicudi Island (Lipari): (a) showing one PB of Filicudi-Le Punte (SIC17ME24) and (b) the land use/land cover classification results, Table S10: Land use/land cover classification results of Filicudi-Le Punte (SIC17ME24) pocket beach and accuracy assessment; Figure S11: Sentinel-2 natural color composite image of Municipality of Malfa in Salina Island: (a) showing one PB of Punta Scario (SIC13ME18) and (b) the land use/land cover classification result, Table S11: Land use/land cover classification results of Salina-Punta Scario (SIC13ME18) pocket beach and accuracy assessment; Figure S12: Sentinel-2 natural color composite image (a) showing one PB of Pollara (SIC14ME19) located on the coast of Malfa and (b) the land use/land cover classification result, Table S12: land use/land cover classification results of Salina-Pollara (SIC14ME19) pocket beach and accuracy assessment. 
Author Contributions: Conceptualization, G.R., S.L., and A.M.; methodology A.M. and G.R. software, A.M.; validation, G.R., S.L., and A.M.; formal analysis, G.R., S.L., and A.M.; resources, G.R.; data curation, A.M.; writing-original draft preparation, G.R., S.L., and A.M.; writing-review and editing, G.R., S.L., and A.M.; visualization, M.C., M.F., and F.G.; supervision, G.R. and S.L.; project administration, G.R.; funding acquisition, G.R. All authors have read and agreed to the published version of the manuscript.

Funding: G.R. is supported by the European Regional Development Fund (INTERREG Italia-Malta) for the Project BESS: Pocket Beach Management and Remote Surveillance System. This research was funded by the European Regional Development Fund (INTERREG Italia-Malta) under the Project BESS: Pocket Beach Management and Remote Surveillance System. Grant number: CUP J71I18000110007

Data Availability Statement: "BESS project website" at http:/ /bess.pa.ingv.it/?lang=it, accessed on 25 May 2021.

Conflicts of Interest: The authors declare no conflict of interest. The funders had no role in the design of the study; in the collection, analyses, or interpretation of data; in the writing of the manuscript; or in the decision to publish the results.

\section{References}

1. Dehouck, A.; Dupuis, H.; Sénéchal, N. Pocket beach hydrodynamics: The example of four macrotidal beaches, Brittany, France. Mar. Geol. 2009, 266, 1-17. [CrossRef]

2. Pranzini, E.; Rosas, V.; Jackson, N.L.; Nordstrom, K.F. Beach changes from sediment delivered by streams to pocket beaches during a major flood. Geomorphology 2013, 199, 36-47. [CrossRef]

3. Pocket Beach Management and Remote Surveillance System (BESS). Available online: http://bess.pa.ingv.it/?lang=it (accessed on 7 August 2020).

4. Pranzini, E.; Rosas, V. Pocket beach response to high magnitude-low frequency floods (Elba Island, Italy). J. Coast. Res. 2009, 50, 969-977.

5. Randazzo, G.; Lanza, S. Regional Plan against Coastal Erosion: A Conceptual Model for Sicily. Land 2020, 9, 307. [CrossRef]

6. Petrişor, A.-I.; Hamma, W.; Nguyen, H.; Randazzo, G.; Muzirafuti, A.; Stan, M.-I.; Tran, V.; Aştefănoaiei, R.; Bui, Q.-T.; Vintilă, D.-F.; et al. Degradation of Coastlines under the Pressure of Urbanization and Tourism: Evidence on the Change of Land Systems from Europe, Asia and Africa. Land 2020, 9, 275. [CrossRef]

7. Costa, H.; Benevides, P.; Marcelino, F.; Caetano, M. Introducing Automatic Satellite Image Processing into Land Cover Mapping by Photo-Interpretation of Airborne Data. ISPRS Arch. 2020, XLII-3/W11, 29-34. [CrossRef]

8. Risandi, J.; Hansen, J.E.; Lowe, R.; Rijnsdorp, D.P. Shoreline Variability at a Reef-Fringed Pocket Beach. Front. Mar. Sci. 2020, 7, 7. [CrossRef]

9. Risandi, J.; Rijnsdorp, D.P.; Hansen, J.E.; Lowe, R.J. Hydrodynamic Modeling of a Reef-Fringed Pocket Beach Using a PhaseResolved Non-Hydrostatic Model. J. Mar. Sci. Eng. 2020, 8, 877. [CrossRef]

10. Colaço, G.; Violante-Carvalho, N.; Arruda, W.Z.; D'Avila, V.; Vilhena, H.; Filippo, A.; Candella, R. Mid-long term characterisation and short term modelling of a semi-protected pocket sandy beach in the Southern Coast of Brazil. Reg. Stud. Mar. Sci. 2021, 41, 101593. [CrossRef]

11. Bowman, D.; Guillen, J.; López, L.; Pellegrino, V. Planview Geometry and morphological characteristics of pocket beaches on the Catalan coast (Spain). Geomorphology 2009, 108, 191-199. [CrossRef]

12. Bowman, D.; Rosas, V.; Pranzini, E. Pocket beaches of Elba Island (Italy)—Planview geometry, Depth of closure and sediment dispersal. Estuar. Coast. Shelf Sci. 2014, 138, 37-46. [CrossRef]

13. Hsu, J.R.-C.; Benedet, L.; Klein, A.H.F.; Raabe, A.L.A.; Tsai, C.-P.; Hsu, T.-W. Appreciation of Static Bay Beach Concept for Coastal Management and Protection. J. Coast. Res. 2008, 24, 198-215. [CrossRef]

14. Cipriani, L.E.; Pranzini, E.; Rosas, V.; Wetzel, L. Landuse changes and erosion of pocket beaches in Elba Island (Tuscany, Italy). J. Coast. Res. 2011, SI64, 1774-1778.

15. Del Grosso, G.; Pranzini, E. Pocket beach erosion: Golfo di Procchio (Isola d'Elba). Medcoast 2003, 64, $1559-1570$.

16. Mannori, S.; Pranzini, E. From agriculture to tourism: A cause of beach erosion. In Proceedings of the 1st International Conference on the Management of Coastal Recreational Resources (Malta), Valletta, Malta, 20-23 October 2004; Micallef, A., Vassallo, A., Eds.; University of Malta: Valletta, Malta, 2004; pp. 79-85.

17. Mateo-Pérez, V.; Corral-Bobadilla, M.; Ortega-Fernández, F.; Vergara-González, E. Port Bathymetry Mapping Using Support Vector Machine Technique and Sentinel-2 Satellite Imagery. Remote. Sens. 2020, 12, 2069. [CrossRef]

18. Randazzo, G.; Barreca, G.; Cascio, M.; Crupi, A.; Fontana, M.; Gregorio, F.; Lanza, S.; Muzirafuti, A. Analysis of Very High Spatial Resolution Images for Automatic Shoreline Extraction and Satellite-Derived Bathymetry Mapping. Geosciences 2020, 10, 172. [CrossRef] 
19. Mugo, R.; Waswa, R.; Nyaga, J.; Ndubi, A.; Adams, E.; Flores-Anderson, A. Quantifying Land Use Land Cover Changes in the Lake Victoria Basin Using Satellite Remote Sensing: The Trends and Drivers between 1985 and 2014. Remote Sens. 2020, 12, 2829. [CrossRef]

20. Politi, E.; Paterson, S.K.; Scarrott, R.; Tuohy, E.; O’Mahony, C.; Cámaro-García, W.C. Earth observation applications for coastal sustainability: Potential and challenges for implementation. Anthr. Coasts 2019, 2, 306-329. [CrossRef]

21. Zhang, A.; Sun, G.; Ma, P.; Jia, X.; Ren, J.; Huang, H.; Zhang, X. Coastal Wetland Mapping with Sentinel-2 MSI Imagery Based on Gravitational Optimized Multilayer Perceptron and Morphological Attribute Profiles. Remote Sens. 2019, 11, 952. [CrossRef]

22. Feng, Q.; Yang, J.; Zhu, D.; Liu, J.; Guo, H.; Bayartungalag, B.; Li, B. Integrating Multitemporal Sentinel-1/2 Data for Coastal Land Cover Classification Using a Multibranch Convolutional Neural Network: A Case of the Yellow River Delta. Remote Sens. 2019, 11, 1006. [CrossRef]

23. Forkuor, G.; Ullmann, T.; Griesbeck, M. Mapping and Monitoring Small-Scale Mining Activities in Ghana using Sentinel-1 Time Series (2015-2019). Remote. Sens. 2020, 12, 911. [CrossRef]

24. Metcalfe, K.; Bréheret, N.; Chauvet, E.; Collins, T.; Curran, B.K.; Parnell, R.J.; Turner, R.A.; Witt, M.J.; Godley, B.J. Using satellite AIS to improve our understanding of shipping and fill gaps in ocean observation data to support marine spatial planning. J. Appl. Ecol. 2018, 55, 1834-1845. [CrossRef]

25. Xi, Y.; Ji, L.; Geng, X. Pen Culture Detection Using Filter Tensor Analysis with Multi-Temporal Landsat Imagery. Remote. Sens. 2020, 12, 1018. [CrossRef]

26. Stiller, D.; Ottinger, M.; Leinenkugel, P. Spatio-Temporal Patterns of Coastal Aquaculture Derived from Sentinel-1 Time Series Data and the Full Landsat Archive. Remote. Sens. 2019, 11, 1707. [CrossRef]

27. Saitoh, S.-I.; Mugo, R.; Radiarta, I.N.; Asaga, S.; Takahashi, F.; Hirawake, T.; Ishikawa, Y.; Awaji, T.; In, T.; Shima, S. Some operational uses of satellite remote sensing and marine GIS for sustainable fisheries and aquaculture. ICES J. Mar. Sci. 2011, 68, 687-695. [CrossRef]

28. Santamaria, C.; Alvarez, M.; Greidanus, H.; Syrris, V.; Soille, P.; Argentieri, P. Mass Processing of Sentinel-1 Images for Maritime Surveillance. Remote. Sens. 2017, 9, 678. [CrossRef]

29. De Sherbinin, A.; Levy, M.; Adamo, S.; MacManus, K.; Yetman, G.; Mara, V.; Razafindrazay, L.; Goodrich, B.; Srebotnjak, T.; Aichele, C. Migration and risk: Net migration in marginal ecosystems and hazardous areas. Environ. Res. Lett. 2012, 7, 045602. [CrossRef]

30. Abdullah, A.Y.M.; Masrur, A.; Adnan, M.S.G.; Al Baky, A.; Hassan, Q.K.; Dewan, A. Spatio-temporal Patterns of Land Use/Land Cover Change in the Heterogeneous Coastal Region of Bangladesh between 1990 and 2017. Remote. Sens. 2019, 11, 790. [CrossRef]

31. Islam, M.R.; Miah, M.G.; Inoue, Y. Analysis of Land use and Land Cover Changes in the Coastal Area of Bangladesh using Landsat Imagery. Land Degrad. Dev. 2016, 27, 899-909. [CrossRef]

32. ENVI Maximum Likelihood Classification Method Descriptions. Available online: https://www.13harrisgeospatial.com/docs/ MaximumLikelihood.html (accessed on 29 January 2021).

33. ENVI Minimum Distance Classification Method Descriptions. Available online: https://www.l3harrisgeospatial.com/docs/ minimumdistance.html (accessed on 29 January 2021).

34. ENVI Mahalanobis Distance Classification Method Descriptions. Available online: https://www.l3harrisgeospatial.com/docs/ Mahalanobis.html (accessed on 29 January 2021).

35. ENVI Spectral Angle Mapper Classification Method Descriptions. Available online: https://www.13harrisgeospatial.com/docs/ SpectralAngleMapper.html (accessed on 29 January 2021).

36. Regione Siciliana-SITR. Digital Orthophotos, with Pixels of $25 \mathrm{~cm}$. The Data Is Published Using a Cache System in Web Mercator Coordinates. Available online: http:/ / www.sitr.regione.sicilia.it/geoportale/it/Metadata/Details/120 (accessed on 30 June 2020).

37. BESS WebGIS Designed for Monitoring and Maintenance of the Pocket Beaches of Sicily and Malta. Available online: http: //51.38.247.246/mylizmap/lizmap/www/index.php/view/map/?repository=bess\&project=bess (accessed on 29 March 2021).

38. Sicilian Population Density. Available online: https://ugeo.urbistat.com/AdminStat/en/it/demografia/dati-sintesi/sicilia/19/2 (accessed on 1 November 2020).

39. Increasing Number of Tourists in Sicily. Available online: https://qds.it/in-sicilia-cresce-il-numero-di-turisti-stranieri-22/ (accessed on 1 November 2020).

40. National Demographic Data 2020 Obtained from the National Institute of Statistics. Available online: http:/ /www.regioni.it/ newsletter/n-3880/del-13-07-2020/istat-diminuiscono-le-nascite-e-anche-gli-stranieri-21451/ (accessed on 9 November 2020).

41. Arsanjani, J.J.; Mooney, P.; Zipf, A.; Schauss, A. Quality Assessment of the Contributed Land Use Information from OpenStreetMap Versus Authoritative Datasets. In Lecture Notes in Geoinformation and Cartography; Springer Science and Business Media LLC: Heidelberg/Berlin, Germany, 2015; pp. 37-58.

42. Viana, C.M.; Encalada, L.; Rocha, J. The value of OpenStreetMap Historical Contributions as a Source of Sampling Data for Multi-temporal Land Use/Cover Maps. ISPRS Int. J. Geo-Inf. 2019, 8, 116. [CrossRef]

43. ENVI Software 5.5 Release Notes. Available online: https://www.13harrisgeospatial.com/Support/Self-Help-Tools/HelpArticles/Help-Articles-Detail/ArtMID/10220/ArticleID/22334/ENVI-55-Release-Notes (accessed on 29 January 2021).

44. ENVI Occurrence-Based Filtering Tools Descriptions. Available online: https://www.l3harrisgeospatial.com/docs/texturefilters. html (accessed on 29 January 2021). 
45. Sicilian Land Use Map According to Corine Land Cover. Available online: http://www.sitr.regione.sicilia.it/geoportale/it/ Metadata/Details/337 (accessed on 30 June 2020).

46. Hütt, C.; Koppe, W.; Miao, Y.; Bareth, G. Best Accuracy Land Use/Land Cover (LULC) Classification to Derive Crop Types Using Multitemporal, Multisensor, and Multi-Polarization SAR Satellite Images. Remote Sens. 2016, 8, 684. [CrossRef]

47. Alonso-Sarria, F.; Valdivieso-Ros, C.; Gomariz-Castillo, F. Isolation Forests to Evaluate Class Separability and the Representativeness of Training and Validation Areas in Land Cover Classification. Remote Sens. 2019, 11, 3000. [CrossRef]

48. Zhang, D.; Fang, S.; She, B.; Zhang, H.; Jin, N.; Xia, H.; Yang, Y.; Ding, Y. Winter Wheat Mapping Based on Sentinel-2 Data in Heterogeneous Planting Conditions. Remote Sens. 2019, 11, 2647. [CrossRef]

49. Mohajane, M.; Essahlaoui, A.; Oudija, F.; El Hafyani, M.; El Hmaidi, A.; El Ouali, A.; Randazzo, G.; Teodoro, A.C. Land Use/Land Cover (LULC) Using Landsat Data Series (MSS, TM, ETM+ and OLI) in Azrou Forest, in the Central Middle Atlas of Morocco. Environments 2018, 5, 131. [CrossRef]

50. Topaloğlu, H.R.; Sertel, E.; Musaoğlu, N. Assessment of classification accuracies of SENTINEL-2 and LANDSAT-8 data for land cover/use mapping. In International Archives of the Photogrammetry, Remote Sensing and Spatial Information Sciences; ISPRS: Prague, Czech Republic, 2016; Volume XLI-B8, pp. 1055-1059.

51. Ahmad, A.; Quegan, S. Analysis of maximum likelihood classification on multispectral data. Appl. Math. Sci. 2012, 6, 6425-6436.

52. Eskandari, S.; Jaafari, M.R.; Oliva, P.; Ghorbanzadeh, O.; Blaschke, T. Mapping Land Cover and Tree Canopy Cover in Zagros Forests of Iran: Application of Sentinel-2, Google Earth, and Field Data. Remote Sens. 2020, 12, 1912. [CrossRef]

53. Chuvieco, E. Fundamentals of Satellite Remote Sensing: An Environmental Approach, 2nd ed.; CRC Press, Taylor \& Francis Group: Boca Raton, FL, USA, 2016; 468p.

54. Petropoulos, G.P.; Vadrevu, K.P.; Xanthopoulos, G.; Karantounias, G.; Scholze, M. A Comparison of Spectral Angle Mapper and Artificial Neural Network Classifiers Combined with Landsat TM Imagery Analysis for Obtaining Burnt Area Mapping. Sensors 2010, 10, 1967-1985. [CrossRef]

55. Talukdar, S.; Singha, P.; Mahato, S.; Shahfahad; Pal, S.; Liou, Y.-A.; Rahman, A. Land-Use Land-Cover Classification by Machine Learning Classifiers for Satellite Observations-A Review. Remote Sens. 2020, 12, 1135. [CrossRef]

56. Warner, T. Kernel-based texture in remote sensing image classification. Geogr. Compass 2011, 5, 781-798. [CrossRef]

57. Haralick, R.M.; Shanmugan, K.; Dinstein, I. Texture features for image classification. IEEE Trans. Syst. Man Cybern. 1973, 3 , 610-621. [CrossRef]

58. Phiri, D.; Simwanda, M.; Salekin, S.; Nyirenda, V.R.; Murayama, Y.; Ranagalage, M. Sentinel-2 Data for Land Cover/Use Mapping: A Review. Remote Sens. 2020, 12, 2291. [CrossRef]

59. Xu, R.; Liu, J.; Xu, J. Extraction of High-Precision Urban Impervious Surfaces from Sentinel-2 Multispectral Imagery via Modified Linear Spectral Mixture Analysis. Sensors 2018, 18, 2873. [CrossRef] 